\title{
3 \\ Inside the Maudsley Child Psychotic Clinic in the 1950s
}

\section{Radicals and establishments}

The 1950s were turbulent, dramatic and provocative times for people interested in social change and its impact on child psychology. The Butler Education Act 1944 had created a revamped education system in which compulsory free education was expanded to secondary level until the age of fifteen; this was in full swing by the 1950s, enabling a revolution in social mobility. ${ }^{1}$ These widespread internal changes were coupled with major shifts at an international level: Britain's imperial strength was being vigorously contested, for example, by the Suez Crisis in 1956, and the global stage was set for the growth of new superpowers, in particular the USA. In many arenas, conservatism and attempts to hold on to old power and traditional forms of knowledge were confronted by radical overhauls of such authority and supremacy.

The 1950s was an important decade for psychological research that took 'society' and social causes within its remit. A new generation of social researchers was beginning to emerge, although they remained partly shackled by the reaffirmation of 'traditional' family values and ideologies after the war. Just as the post-war period had seen a reassertion of women's role in the home and the affirmation of associated cultural dogmas, it also witnessed a reassertion of what Mike Savage has called a 'gentlemanly' form of sociological research, in which uppermiddle-class assumptions were made about normal behaviour and the 'social' was understood within an evolutionary progressive model. Most sociologists working in the late 1940s and 1950s were still privately educated and convinced by a broad modernist agenda. However, in the 1950s a new breed of intellectuals, supported by the grammar 
school system, were beginning to develop radically new ways of thinking about society that took dogmatically assumed cultural and social 'truths' and exposed them for what they were. It was the beginning of an approach to social life that analysed social life itself. ${ }^{2}$

There were many reasons for these rumblings of discontent, most notably the fact that a new generation of motivated young researchers saw opportunities to challenge social norms and create new models of social engagement. One arena in which this was particularly evident was the field of mental health. Inside the walls of long-stay mental health institutions, optimism was growing over the possibility of new treatments for schizophrenia and psychosis in adults, following the widescale implementation of electroconvulsive therapy and the first trials of drugs such as chlorpromazine. This promised revolutions in the asylum approach to mental illness that had prevailed since the nineteenth century in Britain, Europe and the USA. Several other compounds, such as iproniazid and reserpine, were trialled in the rapidly developing new science of psychopharmacology. ${ }^{3}$ At the same time, there was a growing humanitarian challenge to the asylum system, given impetus following the 1953 publication of the report by the Third Expert Committee on Mental Health of the World Health Organization (WHO), which suggested that the 'classical' closed asylum system needed to be replaced with a more liberal model in which treatment was offered in hospitals and outpatient treatment centres and that the freedom and rights of individuals needed to respected. ${ }^{4}$ This led to a growth in the discipline of psychiatric social work as more professionals were employed to cater to people with mental health problems living in the community. ${ }^{5}$

In Britain, new networks were established at the London mental health institutions, the Tavistock Clinic and the Maudsley Hospital, to explore the social causes of mental ill health. At the Tavistock Clinic, psychoanalysts built on ideas proposed by McDougall and Freud, yet they provided far more complex systems, techniques, organisation and procedures with which to explore and investigate these issues. Within these networks, some therapists, especially those based at the Tavistock Clinic, became interested in the social context of psychosis in order to try to make psychotic thinking comprehensible. R. D. Laing, the father of anti-psychiatry, joined the Tavistock Clinic in 1956 after working with serious schizophrenics in long-stay institutions. He would go on to argue, in his first book, The Divided Self, that psychosis was an intense 
version of the 'divisions of the self' that echoed the fragmentation of modern society. Although Bowlby had many reservations about the book, and eight publishers rejected it, it sold 380,000 copies in the UK and Laing quickly became an international celebrity. ${ }^{6}$ It was thus a fascinating, yet problematic, period for the study of severe psychopathology more generally. Laing worked with child analysts Klein, Isaacs and Winnicott, although he focused on adults. Nevertheless, there was clear dialogue taking place between adult and child mental health practitioners about the relation between early development and adult mental illness. Winnicott's ideas about the 'true' and 'false' self, in which a child could build up a 'false' sense of their identity, was developed at the same time, building on his theories of autism in children. The roots laid down by Bleuler and Freud, linking infantile mental life to adult mental illness, found new avenues and roads on which to travel in the expanding interest of society and extreme psychopathology in the 1950s.

The impact of Bowlbyism and general pro-natalism after the war reasserted women's roles as housewives and mothers. Political parties were largely united in the view that married women should not work and there was a general lack of interest in developing provisions for state childcare under Attlee's Labour government, or Churchill or Eden's Conservative governments that followed. ${ }^{7}$ The impact of the Children Act 1948 and the increased sanction given to psychiatric social workers to explore and investigate family life placed mothers in an unusual situation where they were dominant in their home, yet also faced increasing interruption and intervention by Children's Officers, psychiatric social workers and others parties interested in their children's development. Armed with an overarching framework for intervention in child development issues, taken wholesale from the recommendations of the Curtis Committee, state interference into family life grew substantially in the 1950s.

The decade also witnessed growing rifts between approaches taken by different institutions, in particular between those who adopted Bowlby's approach and those who did not. At the Tavistock, no one strayed far from an overarching Freudian model of instinct theory. Even the Tavistock Institute of Human Relations, established in 1947 with funding from the Rockefeller Foundation, drew from Freudian theories of the unconscious in their efforts to explain wider social 'human relations' issues in the field of industrial psychology. ${ }^{8}$ The Tavistock 
sought to develop new ways to think about the subjective aspects of social life and new ways to manage these passively via therapeutic measures rather than full-scale political intervention. In fact, the Tavistock model provided the first prototype institution for Nikolas Rose's now celebrated theory of 'governmentality.' Their goal was to find ways to employ psychological knowledge to enable more sophisticated forms of social governance.

At the Maudsley Hospital, similar moves were made to develop a sophisticated programme to study and intervene in social life, but this never took wider instinct theory, or the unconscious mind, for granted. In the summer of 1948, the Medical Research Council (MRC) provided finances to create a separate unit to investigate psychiatric problems in industry. ${ }^{10}$ The approach was always more process-driven, rather than aimed at exploring the depths of desire and the moral codes created in relation to it. As the director, Aubrey Lewis, described it, they aimed to measure the 'mental and emotional characteristics' of workers in relation to their productivity and social capacity. ${ }^{11}$ Unlike the Tavistock School, which used the psychology of the individual to understand group productivity, the Maudsley School used the psychology of populations in order to understand individual productivity. This distinction was crucial in determining the theories of mind and individual development that researchers at the Institute of Psychiatry then began to produce. Tavistock theorists already had an overarching framework for understanding subjective development drawn from Freud's theories of the unconscious. The Maudsley did not have this in the 1950s, although, as this chapter will demonstrate, there were some who were seeking to develop it.

Hans Eysenck, head of the Psychology Department at the Maudsley, was a critical thinker in the development of supposedly objective tests to measure 'personality', as opposed to intelligence, in Britain. As Maarten Derkson has pointed out, one of his main goals was to draw a distinction between what had previously been termed 'educational psychology' and what he referred to as 'clinical psychology. ${ }^{12}$ He wanted to develop an objective science of psychology based on direct observation that was primarily experimental in nature, yet which also got to the heart of subjectivity and self-hood. ${ }^{13}$ In this way, his work had parallels with Cyril Burt's dream to develop tests to understand subjective development, although Eysenck was not really interested in child 
development. He was very critical of all psychoanalytic concepts of the unconscious, and he also challenged the efficiency of psychotherapy as a curative technique. ${ }^{14}$

Eysenck considered the human personality to be quantifiable in terms of 'introverted' and 'extraverted' reflexes. He worked on developing tests measuring performance and productivity presented as objective measures of personality, often drawing from the work of Neil O'Connor, an experimental psychologist with a strong interest in Soviet psychology. These tests measured performance and productivity but were presented as measures of personality. ${ }^{15}$ Although Eysenck discussed the terms 'introvert' and 'extravert' purely in terms of measurable bodily reflexes, he had in fact taken them from Freud's former colleague Carl Jung, who had claimed that these personality types developed as the result of an individual's unconscious instinctive urges. Jung had modelled these types on Pierre Janet's differentiation between hysterical and psychasthenic characters, though he had broadened these out to include non-pathological character formations. ${ }^{16}$

Eysenck's tests were employed regularly at the Unit for Research in Occupational Adaptation, an adjunct to the Maudsley Hospital funded by the MRC, and also headed by Aubrey Lewis. However, the use of experimental psychology to measure personality types was a long way from psychoanalysis as a comprehensive model of the development of subjectivity and human relationships that was applicable across multiple domains. These psychological tests of 'personality' and subjective awareness slowly trickled down into studies of child development at the Maudsley in the 1950s, but the Tavistock theorists always had the upper hand when it came to understanding the development of human subjectivity because they could easily draw from British instinct theory and theories of the unconscious, without feeling the need to employ methods from experimental psychology. This is why the Tavistock became a dominant force in promoting and publishing theories of child development in the 1950s. Nevertheless, there were moves at the Maudsley to develop new theories of subjective development. However, without the strength and charisma of $\mathrm{BBC}$ personalities such as Bowlby and Winnicott, these theories took some time to get off the ground. This chapter looks at the origins of these theories and the reasons why they were developed. 


\section{The strange case of 'psychotic' children}

By the early 1950s, children classed with 'psychosis', 'schizophrenia' and 'autism' stood at the heart of controversies over the social and emotional development of children, as well as the role of parents, educators, social workers and other agencies in the socialisation of those children. Childhood psychosis was, therefore, an incredibly controversial and poignant topic, touching on all aspects of child development, as addressed by different groups ranging from psychologists and psychoanalysts to parents and government officials. Of course, different professional groups took different approaches to the problem, and this only added to the controversy surrounding the category. Amongst professional child psychiatrists, there was definitely no consensus over the aetiology and prognosis of autism or childhood schizophrenia, and the same was clearly true for psychoanalysts and psychologists who were also grappling with these concepts of early mental development. Health care workers more generally and those engaged with the law concerning child education and welfare thus had very little to work with when it came to legislating for this group of children. Clearly, this did not help in the creation of any solid medical or legal categories to secure services and help for these children, and this group ended up occupying a rather absurd social, political and cultural space.

Although theories of psychosis, schizophrenia, autism, autoerotism and primary narcissism continued to be promulgated within models of normal child development and employed widely in the theories of Susan Isaacs, Melanie Klein, Donald Winnicott and John Bowlby, there were some major ironies that existed for children who actually received a diagnosis of 'schizophrenia' or 'psychosis'. Although welfare measures were put in place to help children who may have been 'deprived of a normal home life, ${ }_{1}^{17}$ and interventions and psychological therapies developed to help children via child guidance services, in fact any child who actually received a diagnosis of very severe psychopathology in the form of 'schizophrenia', 'psychosis' or 'autism' effectively fell through the cracks of any kind of social policy aimed at social and emotional education.

The Education Act 1944, although revolutionary in its claims to expand secondary education for all, made no provisions for such children. Neither did it make any such provision for children with 'mental 
defect'. Although it was not much consolation, 'defective' children were still catered for under the Mental Deficiency Act, even if only with the provision of large-scale institutions. Children diagnosed with 'schizophrenia', 'psychosis' and 'autism' were thus not recognised under any English law and therefore received no special welfare entitlements or provisions. In 1945, the Handicapped Pupils and School Health Regulations that supported the 1944 Education Act legally obliged local authorities to provide special education to all children who could be classed under the following eleven labels: i) blind; ii) partially sighted; iii) deaf; iv) partially hearing; v) delicate; vi) diabetic; vii) educationally subnormal; viii) epileptic; ix) maladjusted; $\mathrm{x}$ ) physically handicapped; xi) those suffering from speech defects. ${ }^{18}$ 'Psychotic', 'schizophrenic' or 'autistic' children were not included. Although these conditions were sometimes smuggled in under the category of 'maladjustment', problems could occur if the child's condition was regarded as a form of severe psychopathology. Services for 'maladjusted' children were not set up to deal with such children and, in practice, most children diagnosed with 'schizophrenia' or 'psychosis' were usually referred swiftly on to the Board of Control as cases of 'mental defect'.

In 1948, the Ministry of Education issued a circular that directly implicated medically trained psychiatrists in the diagnosis and treatment of 'maladjusted' children. This prompted the employment of child psychiatrists in all child guidance clinics across the country, leading to both a growth and a dispersal of the profession. Hospital boards paid the salaries of psychiatrists whilst local authorities continued to pay for the clinic grounds and other staff. ${ }^{19}$ This move did not encourage the treatment of 'childhood schizophrenia' and 'psychosis' because the child guidance clinics were still obliged to refer severe cases on to mental defective institutions. However, it did mean that some child psychiatric departments were able to specialise. It also linked the discipline of child psychiatry more definitively to adult psychiatric sciences. In 1946, Aubrey Lewis required that all psychiatric trainees spend six months in the children's department to ensure that they received a comprehensive education in all psychiatric problems. ${ }^{20}$ In January 1948, the Maudsley Medical School was renamed the Institute of Psychiatry. The Medical School had already functioned as a specialist psychiatric teaching centre, but in the post-war period the Institute of Psychiatry became the major psychiatric teaching centre in the UK, forming one 
limb of the British Postgraduate Medical School, which had established central institutes for all medical specialities across the UK. ${ }^{21}$ When, in July 1948, the Maudsley Hospital was granted National Health Service (NHS) funding, its position as the primary British training centre in psychiatry was confirmed. Yet, the role of child psychiatrists in popularising theories of child development remained very limited and was incomparable to the work of child psychologists and psychoanalysts in generating a popular model of child development. In this respect, the human relations school of psychology remained dominant throughout the 1940s and 1950s. Nevertheless, some child psychiatrists, now dealing with a more specialist clientele, were able to focus on conceptual problems in psychology and education rather than the practical administration of child welfare. 'Mentally defective' children were not technically part of their remit, although the absurdity of this legal archaism was slowly coming to the fore.

Because 'psychotic' children were not mentioned in the 1945 Handicapped Pupils and School Health Regulations, local education authorities did not have to provide special education for them. However, child psychiatrists were incredibly keen to diagnose 'psychosis' in particular, because they thought it would not only help them to develop the science of child psychiatry, but also give them an advantage in developing the finer points of human relations psychology. This led to a peculiar situation where increasing numbers of children were being diagnosed as 'psychotic', yet there was no legal framework to cater for their needs. The early 1950s saw the establishment of several centres for the reception of 'psychotic' children across Britain. In 1953, Dr Elwyn James Anthony and Dr Kenneth Cameron founded a 'psychotic clinic' for the intensive observation and study of children suffering from major psychosis or schizophrenia at the Maudsley Hospital. Cameron had been appointed as head of the Maudsley Children's Department in 1946, after returning from war service in the navy. He had initially joined the Maudsley in 1939 after working with Leo Kanner and Adolf Meyer on a Rockefeller fellowship in Baltimore. Cameron had previously studied medicine in Edinburgh and specialised at the Royal Edinburgh Hospital for Nervous Disorders under David Henderson, whose name, along with that of William Gillespie, was becoming synonymous with British psychiatry through the constant republication of their classic Textbook of Psychiatry. ${ }^{22}$ 
The children who were observed at the clinic during the 1950s were usually aged between three and nine years and were referred from schools, hospitals and child guidance clinics across Britain. All of the children were admitted as inpatients for 'two weeks [of] observation and investigation' as part of the 'psychotic survey programme' and were then referred elsewhere for residential placements. ${ }^{23}$ Many were kept on for treatment as outpatients. Other similar clinics were established in the 1950s, such as Alan Cashmore's clinic at Booth Hall Hospital in Manchester. ${ }^{24}$ In June 1955, Mildred Creak noted that there were 'five centres up and down the country where psychotic children are accepted, mostly on a regional basis. ${ }^{25}$ Anthony and Cameron's clinic was unique because the staff focused on generating observations for the purposes of research. Because of this, 'child psychotics' from other reception centres were often referred to the Maudsley for intense observation. For instance, Cashmore sent virtually all of his Manchester patients to the Maudsley for this purpose. ${ }^{26}$ The foundation of the psychotic clinic strengthened the reputation of the Maudsley as a reception centre for the most severe cases of childhood psychiatric disorder, and as a place where the finer points of psychological theory could be interrogated in depth.

Because the Mental Deficiency, Education and National Health Service Acts made no mention of the concepts of childhood psychosis or schizophrenia, the children diagnosed with these conditions had no legal rights to long-term treatment or education. The Maudsley psychotic clinic was founded partly in order to get 'childhood psychosis' recognised as a legal category and also to reinforce the role of medically trained child psychiatrists in determining the treatment that 'psychotic' children received. On the other hand, because these children were neither theorised nor classified under law, Maudsley doctors were left with a considerable amount of creative freedom in their work, freedom that they would not have had in the treatment of children diagnosed with conditions listed in the 1945 Handicapped Pupils and School Health Regulations.

Although child psychiatry was rapidly developing following the establishment of the discipline at the Maudsley, and as a result of the 1948 Ministry of Education circular that implicated child psychiatrists in the diagnosis and treatment of 'maladjusted' children, there was still a lot of debate over the use of different theoretical models in 
the definition of childhood mental illness. Child psychiatrists began to think more systematically about the definition of childhood schizophrenia as a clinical or medical category, and this was part of a wider shift of interest in the collection of statistics on mental ill health. In 1952, the first Diagnostic and Statistical Manual of Mental Disorders (DSM) was published in the USA with the aim of standardising diagnostic practices in the field of mental illness. It was the first statistical manual to focus on mental disorders. In 1948, the WHO had also taken control of international attempts to standardise all disease categories developed in the International Classification of Diseases (ICD) and had listed a large number of conditions under the heading of 'psychoses', hence the general interest in this particular classification in Europe. However, psychiatrists in the USA were deeply critical of the ICD classifications, and so they developed the DSM. In Britain, clinicians began to draw from both the ICD and the DSM in formulating diagnostic categories in mental illness. For child psychiatrists, the 1952 DSM was more relevant because it attempted to define 'childhood schizophrenia' as a unique condition under the broader heading of psychoses.

In the first DSM, childhood schizophrenia was listed as 'schizophrenic reaction: childhood type'. This classification was subsumed within a wider definition of 'psychotic reactions' in which 'the personality, in its struggle for adjustment to internal and external stresses, utilizes severe affective disturbance, profound autism and withdrawal from reality, and/or formation of delusions or hallucinations.'27 At the same time, it was noted that 'the clinical picture may differ from schizophrenic reactions occurring in other age periods because of the immaturity and plasticity of the patient at the time of onset of the reaction. Psychotic reactions in children, manifesting primarily autism, will be classified here. ${ }^{28}$ This definition drew substantially from the work of Adolf Meyer and was not particularly helpful in establishing a divide between the use of autism as a developmental stage and as a psychopathological category. Nevertheless, it did provoke discussion about definitions and encouraged further exploration of how, precisely, childhood schizophrenia was an extreme form of 'maladjustment', stimulating debate about the particular mental life of children with schizophrenia and how far this could be associated with 'maladjustment'. 
In 1950, the Underwood committee had been appointed to investigate the treatment and prevention of 'maladjustment' in children in Britain and their 1955 report focused on the importance of keeping families together. 'Maladjustment' was used as a broad term to describe a child's inability to control his instincts according to social requirements. The Underwood report was highly influential on the organisation of welfare services for children, in particular on professionals associated with the Kleinian or Tavistock school. ${ }^{29}$ However, it was not well received amongst Maudsley-trained child psychiatrists. This was because it effectively sought to determine their work using the concept of 'maladjustment' as a guide. ${ }^{30}$ In 1955, Kenneth Cameron criticised the entire concept of 'maladjustment' as a working term. He argued that it was simply 'a neutral word utilised to cover a group for whom special provision is required' and was concerned that the concept was becoming reified as a clinical entity in a similar way to the legal term 'insanity' and the social term 'delinquency'. He found these developments disturbing and regarded them as a misunderstanding of both instinct theory and medical science. ${ }^{31}$

Cameron's criticisms sought to silence human relations and Tavistock psychologists who were beginning to attribute all childhood mental illness to insufficiencies in family life and their effect on children's social development. He was infuriated that this model of child development was getting such a good reception at the level of government, when in fact the medical evidence was not there to support it. He argued that the pronouncements of psychology's popularisers were often quite vague when explored in any detail. A few years earlier, Cameron had publicly criticised a speech by Winnicott at the Royal Society of Medicine in which Winnicott had highlighted the normality of 'psychosis' as part of normal developmental stages. Cameron took issue with Winnicott's statement that 'the young child lives in a mad world and only gradually learns to relate himself to reality' and that 'the child analyst has to be able to enter a mad world where reality is dealt with by means of magical thinking. ${ }^{32}$ Cameron was one of the first people to argue that discussing normal phases of development as 'psychotic' and as forms of 'madness' was apt 'to cause alarm and misapprehension' amongst parents and lay people. ${ }^{33}$

Unlike Tavistock 'object relations' theorists who dominated the political application of psychology in the 1950s, child psychiatrists, with 
much less political clout, were beginning to think in more depth about the relationship between mental deficiency and mental illness. This link was being encouraged by work conducted at the Unit for Occupational Adaptation. In the 1950s, a small number of psychologists in Britain had begun to argue that 'mentally defective' children did not need to be consigned to isolated deficiency institutions. After the NHS Act was passed in 1948, mental deficiency institutions became the responsibility of regional hospital boards under the Ministry of Health $(\mathrm{MoH})$. The practices of care used within them were suddenly opened up to new scrutiny by institutions supported by the MRC, in particular the Unit for Research in Occupational Adaptation. In the early 1950s, Neil O'Connor and Jack Tizard used Eysenck's tests to determine whether it was possible to measure 'instability' objectively amongst a defective population. ${ }^{34}$ They argued that the motor skills, performance, intelligence and personality of defectives could be improved so that they might be capable of even employment and life outside an institution, thereby challenging the view that institutional care was the only option.

Shortly afterwards, in 1953, the unit expanded its area of interest to schizophrenic and psychotic populations. This was contemporaneous with the foundation of Anthony and Cameron's psychotic clinic for children. Peter Venables, the chief researcher on schizophrenia at the unit, claimed that schizophrenics constituted 'a population of patients, with in some sense a defined disease, whose magnitude was such as to form a problem of social significance. ${ }^{35}$ Venables, along with O'Connor and others, tested schizophrenic populations using similar measures to those used on defective populations. In particular they measured their reaction times, perception, motor responses and ability to conduct tasks. In one experiment, for example, 'chronic schizophrenics' were given tasks that measured their reaction times to visual stimuli. Venables found that the performances of schizophrenics were slower than 'normal' controls. He reasoned that schizophrenics reacted to stimuli with fatigue or boredom and this inhibited their ability to perform during the task. He then developed tests to prevent these subjects' introversion by distracting them with additional stimuli, such as white noise, during the tasks. This was thought to raise the arousal level via sensory input to the reticular activating system and then by non-specific pathways to the cortex. Venables found that this 'performance' task split the group into 'withdrawn' types, who were less aroused than optimal and 
responded to distraction positively, and 'non-withdrawn' types, who were more aroused than optimal and thus unable to work in the presence of multiple stimuli. ${ }^{36}$

Although the categories of 'schizophrenia' and 'mental defect' remained both legally and socially distinct, the transfer of defective institutions to the management of regional hospital boards under the NHS increased their visibility and raised questions about what the real distinction was. Many psychiatrists thus came to be employed in mental deficiency institutions and many began to assert that deficiency was not an isolated entity and that it could be associated with childhood schizophrenia. For example, in 1952, Gerald O'Gorman, consultant psychiatrist at Borocourt Hospital, Reading, for children and adults classed with mental deficiency, argued that the diagnosis of 'mental defective' was not inaccurate for individuals who had developed schizophrenia in early childhood because 'schizophrenia interrupting normal development ... may so retard a child's progress that he does in fact become a mental defective.' O'Gorman claimed that 10 per cent of adolescents and adults with mental defect had developed this as a result of early schizophrenia. ${ }^{37}$ Mildred Creak also began to argue that the onset of a 'psychosis' in children prevented them from developing normally intellectually and the child therefore developed 'mental defect' as a secondary symptom. ${ }^{38}$

In 1950, Middlesex Mental Defective Colony was renamed Harperbury Hospital and B. W. Richards sent a paper to the Journal of Mental Science highlighting the relationship between mental deficiency and schizophrenia, attempting to figure out whether some of the patients in his institution had, in fact, suffered from a very early psychosis that had been misdiagnosed as a mental defect. 'At this institution', he remarked, 'there are more cases of childhood and pubertal schizophrenia without any fundamental intelligence defect than there are of propfschizophrenia, a term developed by Emil Kraepelin to describe 'dementia praecox' in conjunction with 'mental retardation'. However, Richards would not go as far as Neustadt in dismissing propfschizophrenia entirely. What was clear was that many were beginning to wonder whether institutionalised cases were, in fact, cases of early mental illness, and whether child psychiatrists could in fact assist in preventing the development of such problems. Richards claimed that the early onset of the illness meant that 'schizophrenic' symptoms were unique 
in young children and focused on psychomotor or simple verbal symptoms, such as echolalia, rather than advanced ideational problems such as delusions and obsessive ruminations.

The age of onset continues to act as a limiting factor right into adult life, for the result of the characteristic affective change beginning in childhood is a narrowing of the circle of social contacts. The personality of the patient, never having extended object attachments deeply into the affairs of society with its complex goals, competitive spirit and clash of personalities, gains but a slender hold on the fabric of reality. The clinical picture and psychopathology in adult life are correspondingly threadbare. ${ }^{39}$

By stripping the problem of mental deficiency and childhood schizophrenia down to a problem of early or late onset of mental illness, Richards bypassed the problem of describing early psychological and developmental stages that authors such as Piaget and Isaacs were addressing. However, he did engage with the problem of distinguishing defect and psychopathology, which was not always high on the agenda of psychologists who studied development.

In the USA, several clinicians who regularly came into contact with children classed with 'mental retardation' made similar points. For instance, in 1951, Clemens Benda, Director of Research and Clinical Psychiatry at the Walter E. Fernald State School in Massachusetts for mental retardation, argued that the distinction between mental defect and mental illness in children was artificial and merely a useless application of legal categories from adult psychiatry..$^{40}$ In the same year, M. Bergman from the Newark State School assessed over 300 children who seemed to be both 'defective' and 'schizophrenic' and tried to find out what came first. ${ }^{41}$ Leo Kanner argued that emotional problems could 'interfere' with intellectual functioning in the development of infantile autism. ${ }^{42}$ In short, in the 1950s, childhood schizophrenia was an important issue in the USA and Britain and child psychiatrists were finally beginning to think in more depth about its relationship to 'mental defect.' ${ }^{3}$ They knew that it was central to developing theories of social and emotional development in children, and researchers were beginning to communicate internationally about their theories and approaches. ${ }^{44}$ Louise Eickhoff pointed out that there were transnational differences in the diagnosis of cases and that childhood schizophrenia seemed 
to be less common in Britain than in the USA, although she didn't know why. ${ }^{45}$

By the early 1950s, it was clear that 'psychotic' and 'schizophrenic' children were being used as objects with which to settle controversial discussions on the nature of child development. Many in the USA regarded the study of childhood schizophrenia as a way to challenge behaviourist theories. As George Gardner, from the Judge Baker Guidance Center in Boston, put it, 'no learning experiment, however exquisitely designed', will be able to match clinical observations of childhood schizophrenia in advancing an understanding of the human mind. ${ }^{46}$ In 1953, a major discussion was held on the subject of childhood schizophrenia in the USA. The discussion was remarkably similar to that which had ensued in Britain in the 1940s and rehearsed the problem of behaviourism versus instinct theory and the problem of ego development and the initiation of the Oedipus complex in full. ${ }^{47}$ Everyone thought that the answer now lay in 'schizophrenic children', the new jewels in the crown of psychological theory.

Although Cameron rejected some aspects of 'object relations' theory, in particular the recent fusion of theories of subjective development and ego development in relation to the mother's ability to create a stable emotional setting for child development, he did not reject the project of using childhood schizophrenia as a springboard from which to understand wider problems in child development. The psychotic clinic was largely established in order to clear up confusions and controversies about the category that were rife in the early 1950s.

\section{Inside the first psychotic clinic for children}

My special purpose is the reinstatement of the psychotic within the theoretical framework of our normal practice ... Too often and for far too long we have stood outside and regarded him with increasing theoretical bewilderment as his behaviour continued to transgress the laws of orthodox psychopathology ... Getting inside the psychotic child is by no means an impossible phenomenological undertaking. (Elwyn James Anthony, 1957) ${ }^{48}$

Elwyn James Anthony was born in India and then moved to Britain for medical training just before the Second World War. As a citizen of 
the Empire, he was drafted into the British Army to serve as a doctor where he was 'put into a tent' with John Rickman, a British psychoanalyst who had trained with Melanie Klein and had just started working at the Tavistock Clinic when war broke out. Anthony was then recruited into an army battalion before being placed again with Rickman at Northfields, the legendary military hospital where Rickman, together with Wilfred Bion and Siegmund Heinrich Foulkes, all prominent members of the British Psychoanalytic Society, began a major experiment in the use of group therapy to treat soldiers suffering from 'military neurosis. ${ }^{49}$ As if such diverse experience were not enough, Anthony then trained under Aubrey Lewis at the Maudsley in the late 1940s before being granted a Nuffield travelling fellowship to study with Jean Piaget at the Institut Jean-Jacques Rousseau in Geneva in $1951 .{ }^{50}$ On his return, a new post was created for him as Senior Lecturer in Child Psychiatry, which he took up in February 1952. ${ }^{51}$ This was the first academic post in child psychiatry to be established at the Maudsley. ${ }^{52}$ By the mid-1950s, Anthony was also lecturing at the London School of Economics and presenting frequent papers to the British Psychological Society. He also gave addresses to the London County Council Child Welfare Officers and the Association for Workers of Maladjusted Children. ${ }^{53}$ In 1959, he emigrated to America to join the Washington University School of Medicine in St Louis and in 1960 he joined the Chicago Psychoanalytic Association, where he trained as a psychoanalyst. ${ }^{54}$

In the 1950s, however, he was not psychoanalytically trained and was far more interested in developing the work of Piaget who was, he claimed, like Freud, a 'system maker. ${ }^{55}$ He was interested in bridging gaps between psychoanalytic theory and the theory of developmental psychology, yet he developed this in a slightly different direction than Isaacs, Klein, Winnicott and Bowlby, who had focused on the majority population and on Freudian models in order to develop theories of the mother and child relationship. Instead, Anthony focused on very complex cases that sat at the border of mental deficiency, and then used them as a model for understanding regular developmental psychology in a Piagetian model that employed tests for subjectivity in order to build up an understanding of the development of individual conceptual awareness.

Anthony's work supported Cameron's more practical approach to the assessment and treatment of cases. Cameron's primary interest 
was to classify disease entities in child psychiatry. ${ }^{56}$ When Cameron took charge of the Children's Department, he was finally able to put to use buildings that had been constructed at the end of the 1930s. This architecture enabled the close observation of children from virtually every standpoint and provided the perfect setting for the psychotic clinic. Children could be placed under constant observation by nurses in a centralised ward. Others could be placed in one of the four glassfronted rooms. During play times, all of the children were easily observable in the two bright and spacious recreation rooms.

Although Anthony and Cameron provided the theoretical impetus for the psychotic clinic, nurses conducted the majority of the observational work. This fact is significant as these nurses were largely unhampered by the debates that had been raging over child development and schizophrenia, having been trained principally as domestic attendants who would serve the treatment regimes of doctors. ${ }^{57}$ Nevertheless, they were given a unique role as observers and reporters. In the psychotic clinic, this enabled the creation of vast swathes of material on the behaviour of children who received a diagnosis of 'psychosis', material that could never have been collected by Creak or earlier psychiatrists, who were far too stretched dealing with huge multifarious populations to be able to focus on such detail. Every nurse who reported for duty at the psychotic clinic was given the brief to closely observe the children whom she was also employed to care for. Doctors encouraged them to describe each child's use of language in detail and to illustrate their awareness of other people and objects. As one registrar put it, he was 'interested in observations of [the child's] autistic behaviour when absorbed in his play - arm movements, expressions, verbalisations. ${ }^{58}$

Nurses produced their observational reports in standardised notepads and these reports were read by Anthony, Cameron and other registrars, who would then correct the descriptions. For example, when one nurse began her observations in 1954, she would initially portray her six-year-old male patient using language similar to that of the social workers. Her descriptions were infused with assumptions about the way that children should relate to one another. ${ }^{59}$ However, after further instruction and requests by the doctors to focus on the boy's 'autistic behaviour', she began to produce detailed accounts of the child's individual behaviour and speech. Each action that the child carried out and everything he said were recorded. In particular, the nurse would 
describe all behaviour that appeared to have some bearing on the child's perceptual awareness and his ability to understand concepts. For example, one account read:

When he does play by himself, he walks up and down very precisely with small steps holding his arms out bent at the elbow as if he was wavering on something ... At night when he is in bed he talks to himself a good deal often going over events ... He dresses himself but is very slow needing constant verbal encouragement, 'is this the vest?' he asks, 'is this the right way up?', etc. with every garment. He understands 'upside down' and 'the wrong way up' but is puzzled by 'inside out. ${ }^{\text {'60 }}$

The above observation is typical of those recorded in the 1950s because of the training the nurses received. The aim of collecting these observations was to catalogue the particular conceptual problems that each child was experiencing. From these descriptions, the child's conceptual schema, and their self-awareness, could be ascertained and compared with that of the other children. There was no attempt to use statistical methods to confirm these findings, although the observation of similar behaviour in multiple cases was taken as confirmation.

Central to all of these accounts were detailed descriptions of the child's vocalisations. If children were unable to speak then emphasis would be placed on the noises that they made and whether or not these were imitative. It was thought that these accounts could demonstrate the child's contact with reality by showing his ability to respond to external stimuli. For example, one patient was unable to speak but could mimic 'the noises of things - trains, clocks, things that go "bang". The nurses recorded all the noises that he did make, pointing out that 'he seems to make happy little noises' and that he was able to imitate musical sounds, an indication that he could sense external sounds and respond to them. ${ }^{61}$ Another patient was described as having a 'refusal to speak', although it was noted that he 'whistles beautifully' and 'hums anything from a continuous monotone to ... meaningless monosyllables. He could also 'yelp and scream almost like a puppy'. ${ }^{62}$

If the children were capable of using language then the nurses would record their words in full, in particular noting any set phrases that they used. Many of the children repeated set idioms and phrases and many also exhibited echolalia. Others presented with more unusual speech abnormalities. For example, one patient was reported to 'add the word 
"after" wherever possible and doesn't respond to correction'. This child also had unusual mannerisms in the intonation of his speech. The nurses noted that 'he likes to coin some words in sheer ecstasy especially "it is lunch time" or "I will be last to dinner", etc.' ${ }^{63}$

Nurses would also pay attention to the children's use of personal pronouns that could indicate their capacity to distinguish themselves from others - the fundamental milestone in the psychoanalytic and Piagetian model of child development. Many of the children in the psychotic clinic referred to themselves in the third person or would confuse themselves with other people. For instance, one patient would never speak in the first person and would always refer to herself using her proper name or the name of 'her latest friend. Whenever she misbehaved, she would always deny that she had committed any mischievous acts and would then always adopt the persona of another. ${ }^{64}$ Although not all of the children adopted other personalities, most of them habitually spoke in the third person. In fact Cameron considered that, in terms of diagnosis, any 'inability to distinguish between first and third person ... suggests psychosis. ${ }^{65}$

All of the children's relations were observed and described in language that was dispassionate, detached and devoid of emotion. In 1955, one nurse was able to give an account of a child's aggressive behaviour without making any mention of his feelings. Instead, she used detailed descriptions of his movements and actions to convey his possible thoughts:

Today Arthur was very aggressive towards the staff ... His aggression takes the form of butting with his head, kicking and slapping with the palm of his hand. Arthur makes no attempt to play with the other children but is stimulated by them e.g. Kevin went up and hit Arthur ... on the back for five seconds. There was no response and then Arthur turned round, saw who it was and went up and hit Kevin back, on the head. ${ }^{66}$

In many ways, these accounts were behaviouristic because they focused on stimulus and response and did not attribute any motivations or feelings to the children. However, because the nurses were focusing on 'autistic' behaviour, this would be integrated into a wider theory of autism and subjective development, especially through the work of Anthony.

In the nurses' descriptions of each child's individual behaviour, the child's subjective thoughts were considered to become evident. A description of one child, for example, reported that he 'often stands 
somewhere near the window for long periods twisting curtains around ... [and] sings a lot to himself or sucks some object which gives him great pleasure. When alone, this child 'appeared to be happy most of the time, [though] he often had spells of sudden screaming and biting his arm. ${ }^{67}$ Another was reported to 'kneel on the floor and bang his head once or twice' on a regular basis. ${ }^{68}$ Yet another would engage in other rituals. For example, it was reported that once he 'sat on his bed and screamed for no apparent reason at all ... he then proceeded to hop on his left leg, around the table in the ward. After encircling the table three times he discontinued this. ${ }^{\prime 69}$ All of the nurses' notes are littered with such descriptions of individual behaviour that appeared to have emotional significance only to the child concerned.

For the doctors, the most treasured depiction of a child's individual thoughts and phantasies came in the form of detailed accounts of that child's speech when they were engrossed in thought. Nurses would record every single word and phrase that the child spoke when they observed these situations. The following account quotes in some detail the speech of an eight-year-old girl. Similar accounts cover scores of pages. They represent occasions where the children described their own desires and emotions and were thus viewed as the only legitimate documentation of these phenomena:

The child speaks to herself continually. Her conversation:

She wants to go out to tea, do you want to go out to tea, Friday, you ought to go. Your handies cold warm them up (puts them on radiator) dicky birds, little baby ones, do you want to sit on that (potty) sit on the potty, put her there. Little monkey get out of the way. See her handy pandies are freezing (waves hands about). Do your business in the potty, sick in the potty (she was sick this morning). See the bunny. You're not well, you've got a nasty chill you don't want to come, we'll see these bunnies after dinner. Have you been a good girl today, not well, bunnies asleep, see bunnies presently. (Giggles to herself and runs hands over the radiator). Don't keep on asking me questions. You get the key get him out of my way, let him out of the hutch, not well enough 72 days 'til Christmas when you get a bigger girl you will be quiet (holds hands over her ears) there'll be trouble. Get a good hiding don't sick on the floor. There's a potty here. (Gets the potty and puts it on the window sill) ${ }^{70}$ 
These words were thought to be a window onto psychotic states of mind. For Anthony and Cameron, who oversaw the production of this discourse, it could reveal the thinking processes that later led to adult schizophrenia.

Although the impetus for these descriptions came from Anthony and Cameron, it is clear that these nurses' reports began to guide the direction that psychosis research took. This is essentially because the nurses began to develop a general discourse for describing psychotic children and their activities. This was the beginning of a new language of autism. In 1957, Anthony argued that one could only truly understand the psychotic mind if one developed a language that could describe both the inner and the outer perceptions of the psychotic individual. Using poetic terms, Anthony once described the child psychotic's mental state as 'the world of the very young infant set in the twilight of consciousness'. This world

will sometimes be overwhelming in its sensation, sometimes wild and frightening, sometimes flat and uninteresting; time will be reduced to the 'here and now' and space to the subjective needs of the moment; objects will sometimes be permanent and sometimes impermanent, sometimes meaningful and sometimes meaningless. ${ }^{71}$

Anyone attempting to observe this phenomenon must be prepared to enter into this world and to understand the way psychotic children conceptualised both phantasy and reality. Children who could use language to describe their conceptual 'worlds' were prized objects at the psychotic clinic because they provided the most direct access to this inner reality. The experiences of child 'psychotics' that Maudsley nurses began to document were unique because they described children's thought independently of their relationships to others. All thought that was considered to be 'psychotic' was defined by these discursive rules and boundaries.

The observational method developed by Anthony and his work on childhood psychosis was extremely influential and was quoted by many authors of the 1950s and 1960s, including Michael Rutter, who based his first classifications of psychosis and autism on the work of Anthony and, by proxy, the nurses at the psychotic clinic. ${ }^{72}$ 


\section{Testing, testing, testing}

All of the children in the psychotic clinic were given a battery of tests on arrival in order to determine their physiological functions and their levels of intellectual and social development. These included X-rays, brain scans and tests on the nervous system conducted by doctors, as well as a large number of standardised psychological tests conducted by psychologists. Every child was tested using electroencephalography in order to measure the electrical charges in their brain. This built on Piaget's work on electroencephalography and child development and the theories of alpha, beta and gamma rays in developing brains he had presented at a major WHO conference on the psychobiological development of the child. ${ }^{73} \mathrm{X}$-rays would be taken of the child's wrists to measure the age and structure of their bones. If it was thought that there may be any damage to the child's head, then X-rays were also taken of their skull. Wasserman and Kahn tests for syphilis were given, as were cardio-lipine tests for thrombosis. Some of the children were also photographed or filmed. Anthony produced a short film on childhood psychosis using footage from the clinic that he presented at the Second International Congress in Psychiatry in Zurich in $1957 .{ }^{74}$

A standardised form covering aspects of the child's nervous system, circulatory system, respiratory system, alimentary system and urinary system would be completed in full. The form was based on a tradition of nerve and reflex testing that drew strongly from the neurological sciences. The child's weight, height and complexion would be recorded, as well as any 'deformities or stigmata'. In measuring the child's nervous system, 'involuntary movements', 'tremors' and 'tics' would be noted, as well as 'deep reflexes', 'superficial reflexes' and every twitch, reflex or expression that would indicate the functioning of the cranial nerves (Figure 1). This information was collected in order to assist Anthony and Cameron in their measurement of biological functioning at the sensory-motor level and its influence on the child's psychological state.

Standardised psychological tests were applied by psychologists employed solely to test the children. H. Gwynne Jones, M. Newell, Patricia Audley and A. D. E. Schonfield all worked at the clinic as staff psychologists in the 1950s, along with trainee clinical psychologists. The most common form of intelligence test used on psychotic children at the Maudsley in the 1950s was the Wechsler Intelligence Scale for Children (WISC). 


\section{CONDITION ON ADMISSION}

An entry, positive or negative, to be made if possible against each heading. This may be in the briefest form which is complete and intelligible. If space does not permit adequate entry refer to separate note. Statements of patients to be distinguished by inverted commas.

Height Weight Tpr. P. R. Nutrition

General bodily health Relation of appearance to age

General development and build

Complexion Colour of irides Cornea, Conjunctiva

Skin eruptions, etc.

Hair on cranium; on Face;

Any anomaly of Cranium, Face, Ears, Palate, etc. Bones and joints

Deformities and stigmata

Signs of old or recent injury

Signs of sinus infection

Thyroid

Lymphatic Glands

\section{NERVOUS SYSTEM}

Symptoms

Sleep

TRUNK AND LIMBS Trophic State of Skin etc.

Any wasting of muscles

Pareisis

Muscular tone

Involuntary movements, tremors, tics, etc.

$\begin{array}{lllll}\begin{array}{l}\text { Deep reflexes K.J. } \\ \begin{array}{l}\text { Superficial reflexes } \\ \text { Coordination }\end{array}\end{array} & \text { B.J. } & \text { T.J. } & \text { S.J. } \\ \begin{array}{llll}\text { Cutation } \\ \text { Ste }\end{array} & & \text { Gait } & \end{array}$

Cutaneous and deep sensation

Pain and paraesthesiae

CRANIAL Nerves $\quad$ I. Smell II. Vision Fundi

III, IV, VI Exopthalmus Ptosis Strabimus Diplopia

Movement of eyes

Nystagmus

Pupils. Outline R. L. Consensually R.

Jaw muscles Sensation of face

II Voluntary facial movement

Prevalent expression

III Hearing Tinnitus Vertigo

IX, X, XI, XII Movements of Palate Tongue

Swallowing Articulation and Phonation

Movements of Expression

L. To accommodation R. L.

Reflexes corneal, conjunctival

Furrows and expression lines

Aural discharge

\section{CIRCULATORY SYSTEM}

Symptoms Oedema Cyanosis Anaemia

Flushing Dilated Capillaries Varicose Veins

Condition of arteries

BP

Pulse Circulation in Extremities

Sweating

Figure 1 Facsimile of the first page of 'Condition on Admission' form used to collect information from children in the psychotic clinic in the 1950s (MHCP/A) 
David Wechsler had studied under Charles Spearman at University College London and went on to serve as chief psychologist at the Bellevue Hospital in New York from 1932 to 1967. In 1939, he published the Wechsler-Bellevue intelligence test and followed up with several revisions that increasingly divided Spearman's concept of ' $g$ ', or general intelligence, into different parts. ${ }^{75}$ In 1949, Wechsler published the Wechsler Intelligence Scale for Children, a testing schedule that divided a child's IQ level into two different fields. If a child was able to complete certain 'performance' tasks, such as the arrangement of pieces to form a model of a car, or the coding of geometrical shapes, then he could receive a high IQ score in that area, even if he was unable to score highly on the 'verbal' tests. This meant that even mute children could be rated with very high intelligence scores in non-verbal areas. Wechsler's tests also allowed for interruption or spoiling so that if a child refused to finish the tests or spoilt his paper in some way then the IQ values could still be calculated. ${ }^{76}$ In the psychotic clinic, there were frequent cases of 'spoiling' and many of the test papers were left uncompleted. Up until the 1950 s, children with such test papers would have been written off as 'defective'.

Other tests used in the Maudsley psychotic clinic measured specific aspects of each child's motor development and perceptual functions. These included the Vineland Social Maturity Test, the Rorschach test, the Goodenough 'draw a man' test, the Romberg test and the 'whirling' test. The Vineland Social Maturity Test was developed by Edgar A. Doll, who was based at the Vineland Training School for FeebleMinded Children in New Jersey. The test was published in 1935 when Doll was head of the psychological laboratory. He succeeded Henry H. Goddard and S. D. Porteus in this post, both of whom had been very influential in the fields of intelligence testing and eugenics. Goddard translated Binet's tests into English between 1905 and 1908 and publicised them in the USA, just as Burt publicised them in Britain. ${ }^{77}$ Doll's test was designed to measure not only the child's conceptual awareness but also his competence in usefully applying this conceptual knowledge in the management of his life. For children between the ages of one and eleven, it would rate such things as whether or not, when prompted, the child 'walks about room unattended', 'transfers objects', 'gives up baby carriage', 'discriminates edible substances' or 'walks upstairs unassisted'. The more tasks that the child could complete, the higher his social age 
was rated. This was then calculated with his actual age to produce a 'social quotient', or SQ, that was unrelated to his IQ.

The Rorschach or 'inkblot' test was first published in $1921 .{ }^{78}$ Its creator, Hermann Rorschach, had trained in Zurich and Neuchâtel, graduating in 1906. He had studied with Bleuler and was greatly influenced by the work of Jung. In 1912, he published his doctoral work, 'On Reflex Hallucinations and Kindred Manifestations'. This addressed the question of how hallucinatory experiences could exist when they related to states of being that were physiologically impossible. This work was written in the frame of Bleuler's model of associationism in psychology. ${ }^{79}$ Rorschach's interest in hallucinations was coupled with a growing fascination with the way in which patients free-associated to images. His inkblot tests were aimed at standardising visual material to which patients could respond with associations. Rorschach's tests were not generally well received in Britain, ${ }^{80}$ but they were employed in the Maudsley psychotic clinic. Children's responses were thought to reflect their phantasies and thus indicate whether they inhabited a psychotic mind-state. If they took a long time to respond, or made 'bizarre' suggestions, it was thought that their phantasy life was unusually active and this was taken as indicative of developing or existing schizophrenia.

Some tests employed by Anthony and Cameron were specific to the identification of schizophrenia in children. In 1952, the 'whirling' test was evaluated by Yale Kramer and other doctors from the Department of Pediatrics at Bellevue, who 'whirled' 700 children in order to see whether the test could be used alone as a diagnostic tool. They argued that it was useful, though not decisive, in identifying schizophrenia. ${ }^{81}$ At the Maudsley, the test was employed as a measure of the child's motor co-ordination and his sensory-motor functions. It was similar to the Romberg test in which children were blindfolded and tested as to their spatial awareness. All of these tests could help to build a picture of the child's internal conceptual framework and his sensory-motor functions, and his efficacy in determining external reality.

The 1950s saw the first systematic application of tests to schizophrenic children in order to ascertain what their problem really was. ${ }^{82}$ Play techniques and the discussion of projective mechanisms by psychologists, such as Lowenfeld, encouraged the observation and analysis of drawings by schizophrenic children in order to ascertain the perceptual problems that may accompany the condition.$^{83}$ Lowenfeld argued 
that her 'world technique' was a tool of particular value for the study of schizophrenic children. Children were presented with trays of sand and miniature toys representing their everyday life and experience, and through this they were expected to express their emotions and inner worlds. ${ }^{84}$ Other North American writers were interested in the drawings of child schizophrenics as representative of their 'perceptual problems', such as J. Allison Montague from Columbia University. ${ }^{85}$ In order to test the children's bodily boundaries, at the Maudsley children were asked to 'draw a man' and the picture was then analysed. Some of the psychotic children at the psychotic clinic were unable to complete the task at all, which was thought to signify a complete inability to recognise others or an inability to represent reality. Others included disturbing features or omitted vital features such as the body or the eyes. ${ }^{86}$

Anthony and Cameron developed their own unique logic regarding which tests to apply to which particular children at the clinic. For example, in 1952 one six-year-old child was described by M. Pines, a registrar in the psychotic clinic, as 'a very seriously disturbed child presenting signs of autism and speech disturbance involving reversal of pronouns, obsessional traits, marked anxiety and phobias. ${ }^{87}$ On admission the boy was given the WISC verbal and performance tests, the Goodenough test and the Rorschach test. Unlike many other psychotic children, his verbal and performance test scores were similar, though they were both in the low range. These results were not thought to be wholly reliable as the child 'did not really make an effort' and was 'dreamy and slow to respond'. However, even when making an effort he did not appear to understand the questions concerning comprehension and gave many unusual responses. For example, when asked 'what should you do if you cut your finger', he replied, 'I take the blood out'. In the Goodenough test he scored very highly, though he gave the man unusual features such as 'a penis, navel and breasts, and on one foot he drew skates'. In the Rorschach tests he refused to co-operate and 'finally nearly got into a white rage so that the test was discontinued'. The psychologist reported him as 'certainly not defective', and noted that he shows 'emotional responsiveness and is not completely withdrawn socially'. However, she also pointed out that 'some of his drawings have bizarre features' that may indicate 'schizophrenic signs', even though this could not be verified in the Rorschach test. ${ }^{88}$ According to Anthony, test results such as these indicated that the child's 'educational backwardness is secondary 
to his mental disturbance which corresponds to an autistic type of childhood psychosis. ${ }^{89}$ In other words, the child's lack of subjective awareness led to educational problems.

Anthony and Cameron used their arsenal of testing methods to identify the primary problem that they thought led to a child's psychosis. For example, in 1958 one eight-year-old girl was referred to the clinic and given a preliminary diagnosis of 'childhood schizophrenia'. Her inpatient summary stated that she was hostile to her younger siblings, had a 'speech defect', could not write and had been excluded from school 'after three weeks because she took no notice of anybody. ${ }^{90}$ On the reflex tests, she was found to have limited movements of expression in her face and possibly no sensation. Her 'prevalent expression' was recorded as 'perplexed. The psychologists tested her using a battery of tests that did not require any verbal responses. These included the Goodenough test and the WISC performance scale, as well as 'picture vocabulary' and 'progressive matrices' tests. Although she scored well on the Goodenough test and was rated with an IQ of 86 , she scored very badly on the WISC performance scale. Her low scores were thought to reflect her problems 'involving abstraction of ideas e.g. number and classes of objects'. In several tests, she appeared unable to understand what was being asked of her and would merely repeat the instruction and move the test materials around randomly. Though given no formal spoken or written tests, her speech was recorded on tape for a period of forty minutes, during which she was given small toys and pictures to look at. It was noted that 16 per cent of her speech was echolalic and that she had huge difficulty in pronouncing consonants. In cases such as this, Anthony and Cameron would consult other doctors, in particular, neurologists, over the speech problems of 'psychotic' children. This girl was referred to Dr Hulbert at the West End Hospital for Neurology and Neurosurgery with an accompanying question: 'Does she have a specific neurological speech defect in addition to the speech disorder associated with her psychosis? ${ }^{91}$ Hulbert responded that she had 'a mild dyslalia with defect of intonation', but that 'speech therapy was unlikely to help until her level of cooperation [had] been improved from the psychiatric angle. $\mathrm{He}$ thought that 'psychiatric' treatment would help her to understand 'the mechanics involved' in the pronunciation of words. ${ }^{92}$ Cameron and Dr Kreitman, his registrar, acknowledged that distinguishing between the girl's speech defect and her psychosis was an 'extremely difficult 
and perhaps insoluble problem. ${ }^{93}$ However, they all agreed that speech therapy should be attempted as this may lead to improvements in her psychotic condition. The conclusion in this case was that the girl's problems were the result of her inability to speak and think conceptually, rather than her phantastical and psychotic state of mind being the cause of her speech problems. ${ }^{94}$ Cameron would refer to this and similar conditions as 'primary backwardness with a psychotic overlay. ${ }^{95}$ In cases such as these, the child's phantasy life was not of primary interest.

Psychological tests could help to distinguish between different forms of child psychosis that were observed at the psychotic clinic. The use of standard psychological tests alongside reflex and medical tests meant that a child's conceptual development could be tallied with their functional abilities. The results formed the backbone to new theories of psychotic phenomena in children that divided 'psychotic' children into types in an attempt to ascertain causes. In a 1957 article, Anthony described the results of tests he had been conducting on psychotic children that aimed to test their reactions to stimulus in order to rate their degree of 'egocentricity' and their ability to distinguish themselves from others. The majority of these experiments drew from tests devised by Piaget. For example, in 'the test of three mountains', psychotic children were shown a series of toy mountains. A toy child then climbed each of these mountains and took a picture at the top. The children were then asked to identify the position from which each photograph was taken. In order to complete the test successfully, the child must be able to see things from the point of view of the toy child. ${ }^{96}$ It was predicted that all psychotic children would score highly on this perceptual test for 'egocentricity' and the test results confirmed this prediction. Given that Piaget was the first person to develop the theory of autism in relation to children, it is entirely appropriate that he was also the first person to develop a test for 'egocentricity' or subjective awareness for children, which was then followed up by Anthony.

Prior to the establishment of the psychotic clinic, and Anthony's appointment as Senior Lecturer in Child Psychiatry, children who were referred to the Maudsley in the late 1940s and early 1950s and diagnosed with schizophrenia or psychosis were often given very intensive and invasive treatments. These ranged from insulin shock and drug therapies to intensive psychoanalytic treatment. For example, in 1955, Cameron reported the case of one psychotic girl who had begun 
to deteriorate at the age of three and who was treated at the age of eight 'by insulin comas without benefit and during the course of treatment died from subarachnoid haemorrhage. ${ }^{97}$ A nine-year-old boy admitted in 1950 was given insulin shock treatment over a period of twenty-six weeks. ${ }^{98}$ After four weeks of treatment, the patient was seen by Cameron, who is reported to have commented that 'where before insulin treatment he was a thin miserable, mute child, he is now a fat happy mute child.99 Other than this development the treatment did not alter the child's condition, and Cameron later admitted that 'insulin treatment has been disappointing in pre-pubertal cases. ${ }^{100}$ This bleak episode in the treatment of 'psychotic' children in Britain was a reflection of the parallels drawn between adult and infantile 'psychotic' thought. However, the close parallels and extreme experimentation were still not on a par with the aggressive approaches that had thrived in the USA. There is no evidence that any children were treated with insulin shock after the late 1950s at the Maudsley. This change was influenced by the work of Anthony, which viewed autism, psychosis and schizophrenia as often closely aligned to other forms of 'normal' or typical development.

In the late 1940s and early 1950s, some 'psychotic' children were given intensive psychotherapy at the Maudsley, usually under the supervision of Clifford Scott. ${ }^{101}$ Scott was a medical doctor who had studied at the University of Toronto and Johns Hopkins University in Baltimore. In 1931, he moved to London where he joined the British Psychoanalytic Society and was assigned to Melanie Klein for analysis. By the late 1940s, he was director of the London Clinic of Psycho-analysis and a senior psychotherapist at the Maudsley, where he worked psychoanalytically with both adults and children. In 1948, he had a paper accepted in the prestigious British Medical Journal that defended Klein's theories on the origins of depression. As he put it, depression

often occurs early in the first six months of life. It must also be remembered that the tests of reality which can be made at such a period are of an infantile type. The intensity and explosiveness of the infantile satisfactions and rages interfere with perception of reality, both inner and outer. The way each satisfaction and each rage is shown colours the outer world and the inner world by rapidly acting and by complicated types of introjection and projection. ${ }^{102}$ 
Other therapists were also employed at the Maudsley child clinic and many used Kleinian theory and technique. For example, one boy was given 'psychoanalytic treatment' for four months by Dagny Oftedal in the early 1950s. Oftedal described her technique as follows:

It was felt to be important to deal as much with the patient's behaviour and his relationship with the therapist as with content of phantasies. His evidence of emotional contact, his fear of showing any affect, and after the affect was obvious, his reluctance to admit that he was angry with the therapist, or fond of her, was constantly interpreted to him. ${ }^{103}$

Although such therapies were reported to have some efficacy by the therapists themselves, Anthony and Cameron thought that they were often followed by relapse. After the opening of the psychotic clinic, children who presented with psychotic symptomatology were very rarely treated with psychoanalytic therapies.

In place of insulin shock therapy and intensive psychoanalytic therapy, the establishment of the psychotic clinic saw the introduction of more sedate therapeutic measures, in particular 'occupational therapy' or 'school therapy'. 'Occupational therapy' was usually conducted by nurses. ${ }^{104}$ 'Instructions' were given by doctors who stated that the desired outcome of the treatment was 'socialisation'. In contrast to the 'socialisation' encouraged by psychiatric social workers, the 'socialisation' practised by nurses was focused on preventing bad behaviour rather than analysing and interpreting the child's relationship to others. For example, Anthony described one child admitted in 1953 as 'functioning at a very early social level and his contact with people is intermittent'. Occupational therapy reports pointed out that

He plays OK with the sand - letting it run through his fingers or watching it drop on the floor, and also eats it, but makes no attempt to play constructively with it. This and shutting himself in the small cupboards both activities which the psychotic children indulge in more consistently than any other, is what he prefers to do and has any drive to do. He spends a lot of time wandering around the room throwing things on the floor, usually things that the other children are absorbed in. This is done in a rather vague unpredicted and yet compulsive way. ${ }^{105}$

Therapy focused on upgrading his social level. Nurses were instructed to 'encourage him to be independent in dressing, eating, etc'. The aim was to enable the child to live without institutional support rather than 
to engage with his fantasy life and improve his relationships. This kind of 'occupational therapy', also referred to as 'training', was thought suitable for children with low IQs who made up the majority of the psychotic clinic's population.

Almost all of the children who were admitted to the psychotic clinic in the 1950s were referred to 'special schools', 'training' or 'defective' institutions when they left. The doctors and clinic staff considered the question of where to put each child as one of 'disposal'. This word was used on the standardised admission and discharge form and was often quoted in letters to County Medical Officers. The following extract is from a 1958 letter written by Cameron to a consultant paediatrician in Lancaster concerning a six-year-old child who was under consideration for disposal in a defective institution:

By now it is clear that this boy developed a psychotic illness at the very end of 1955, of which you must have seen the initial phase of withdrawal, muteness, loss of toilet habits, etc. At present he is active and lively, does not speak except a few words but whistles tunefully, and is improved in his habits: but he does not relate in any ordinary way to his surroundings, performing odd little mannerisms which are presumably related to his inner fantasies. The prognosis is not good and he may have to be dealt with ultimately under the mental deficiency acts. ${ }^{106}$

It was this kind of reasoning that led Cameron and others to refer psychotic children with potential 'inner fantasies' to institutions designed to deal with 'defectives'. However, most of these children were still kept on the books of the Maudsley, thereby generating a population of children who were living in defective institutions and residential special schools, yet were also registered at the Maudsley. Cameron, Anthony and others kept in contact with many of these institutions and formed very strong institutional, intellectual and administrative bonds with many of them.

Many 'psychotic' children who were thought to have the potential to develop through education and speech therapy would be sent to one of several Rudolph Steiner schools across Britain. The 'Camphill Rudolph Steiner Schools' had their headquarters in Harley Street, London, where their superintendent, Karl König, worked in conjunction with the Medical Officer, Neil McArthur Lees. ${ }^{107}$ König, who had trained in medicine in Vienna, acted as consultant for cases at the Larfield Hall School in Kent, the Salmon's Cross School in Surrey and the Murtle 
House School in Aberdeen, where former patients of the psychotic clinic were sent. Staff at the Steiner schools wanted to know the kind of information that Maudsley doctors were interested in. For example, the principal of Salmon's Cross School wrote to Cameron in 1955, including reports of a case, adding that 'there is of course much more that can be said about him and I shall be very glad to do so if you think the enclosed reports are not quite sufficient. ${ }^{108}$ Cameron and König also corresponded on the diagnosis of certain cases. ${ }^{109}$ In the majority of cases, the placements were successful, although in some cases they were not. For example, one child was referred to a Steiner school but was later referred back to the Maudsley because 'he shows a typical schizophrenic grin, he shouts, often repeating in an obsessional way some indecent word. He quite obviously has hallucinations of some sort and he cannot be kept in class with other children. ${ }^{110}$ This child was later admitted to an institution for mental defectives.

After the foundation of the psychotic clinic, Maudsley doctors ceased to maintain close contact with child guidance clinics or training schools that analysed and treated children using psychoanalytically influenced therapeutic methods. Although Anthony and Cameron were sympathetic to psychoanalytic theory, they were suspicious of many forms of psychoanalytic therapy for children. For example, they did not support methods based primarily upon developing a child's relationships rather than their intellect. They also supported parents who sought to remove their children from institutions where these forms of therapy were practised. For example, one child had been diagnosed with 'general backwardness' and had been treated by a play therapist at Ilford child guidance clinic. He was removed by his parents because they found his condition to be deteriorating instead of improving. He was then sent to the psychological medicine department of a major UK hospital, where the clinician deemed that 'this type of child cannot learn from experience.' It was on this assertion that the parents referred him to the Maudsley for a different opinion, and he was later accepted as a patient in the psychotic clinic. ${ }^{11}$

In cases where a psychotic child was deemed to be mentally defective, there was often an appeal against the decision by the parents. Correspondence and discussions pending the appeal could take place over months or even years as the parents sought to postpone decisions, and these would continue if the appeal was upheld. Maudsley 
doctors corresponded with County Medical Officers and representatives of local education authorities. For example, in 1954, the Principal School Medical Officer of West Sussex County Council, J. S. Bradshaw, claimed that one child who was attending Anthony's psychotic clinic was, in the words of the Education Act 1944, 'suffering from a disability of mind of such a nature or to such an extent as to make him incapable of receiving education at school'. The child's parents were unhappy with this ruling and claimed that their child should be sent to a special school rather than a defective institution where he would be 'doomed for life'. Anthony wrote to Bradshaw, claiming that 'it is difficult to explain to parents that there is nothing wrong with the child's brain and yet the child is not normal'. Nevertheless, Anthony engaged in discussions with the parents until they accepted the ruling. ${ }^{112}$

By the 1950s, some mental defective institutions for children were beginning to market themselves as pleasant places of residence in order to avoid such resistance by parents and to align themselves with the special schooling system rather than the asylum system. Prospectuses put a positive gloss on the treatment that children received: for example, St Agnes' Home School prospectus stated that the school was located in beautiful 'country surroundings' and that 'the life of the children is a very happy one.' Children would be given 'care and training combined with a happy and healthy home life [with] the utmost importance ... attached to training in personal hygiene and good habits.' ${ }^{113}$ If a 'psychotic' child did reach the end of the line in the 1950s, then they were lucky if they reached an institution such as this an institution such as this.

It has become commonplace to claim that the closure of asylums at the end of the 1950s was a consequence of improved drug treatments that enabled patients to be treated in the community. ${ }^{114}$ However, there were other highly significant factors that led to the new policies assumed by asylums and mental defective institutions after 1959. The move towards discretionary admission of defective children first arose following the National Health Service Act in 1948 when some mental defective institutions began to invoke Section 3 of the Mental Deficiency Act to admit child patients at the behest of their parents without a magistrate's order. Before 1948, this section of the Act had only been used to admit patients into private hospitals. However, the changed status of mental deficiency institutions after 1948 left the issue 
of informal admissions ambiguous. According to L. T. Hilliard, consultant psychiatrist and physician superintendent of the Fountain Mental Deficiency Hospital, Tooting, there was initially some uncertainty over the legality of Section 3 admissions, but their increase put pressure on the Ministry of Health to reconsider their stance on the requirement for certification. ${ }^{15}$ On 21 January 1952, Ministry of Health Circular $5 / 52$ was issued, which enabled mental deficiency hospitals to admit uncertified patients on a short-stay basis not exceeding two months. By 1955 , nearly 2,000 uncertified cases had been admitted to mental defective institutions on a short-stay basis. ${ }^{116}$ After the closure of deficiency institutions following the 1959 Mental Health Act, Section 5/ 52 was still retained but was reformulated as a clause to allow for the short-term admittance of patients to hospital for 'social' reasons. Many hospitals then began to admit children for weekends or short breaks if it was felt that their families needed respite. ${ }^{117}$ These changes were largely driven by the establishment of short-stay admissions for children with psychosis.

The conceptualisation of the 'psychotic' child

In 1958, the European Journal of Child and Adolescent Psychiatry published an article by Anthony entitled 'An Aetiological Approach to the Diagnosis of Psychosis in Childhood'. The article was very well received and was later quoted by most Maudsley researchers on autism such as Lorna Wing and Michael Rutter. ${ }^{118}$ In the article, Anthony presented 'the concept of psychosis ... [in] relationship with other psychiatric disorders of childhood. ${ }^{119}$ It was an attempt to merge psychoanalytic theory and Piagetian theory with the sciences of infant observation, symptomatology and natural history in the Kraepelinian sense of tracking the development of an illness over time.

Anthony argued that within all cases of childhood psychosis and autism, there were 'components of three basic conditions of malfunctioning. These were, first, an inability to form a coherent and stable sense of self; second, an inability to 'cathect' internal experiences accurately, leading to 'difficulties in interpersonal relationships and displacement of affect onto things'; and, third, 'a confusion of self and non-self and disturbances in the perception of the self.' ${ }^{120}$ Anthony named this 
last problem 'a-dualism', borrowing the term from Piaget. ${ }^{121}$ This triad of 'malfunctions' was an original way of perceiving problems of selfidentity and would later form an important basis for all psychosis and autism research at the Maudsley, in particular the work of Lorna Wing and Michael Rutter.

Anthony thought that although all autistic and psychotic children displayed abnormalities in ego development, these disturbances followed different trajectories and so could not all be classed under a general term. He identified three different developmental stages during which childhood psychosis could strike, drawing from a similar claim by Lauretta Bender based on her understanding of Klein. ${ }^{122}$ These different ages of onset did not designate different conditions but merely different outcomes that were dependent upon the child's psychological maturity. In the first age group, which Anthony thought corresponded most closely with Kanner's description of infantile autism, 'the psychotic process fuses with earliest infancy' and the child is unable to respond normally to external bodily contact. Such children were often misdiagnosed as defective or deaf. In the second age group, in which onset occurred between the ages of three and five, the child suffered 'a massive regression to an autistic level'. This caused a 'turbulent' phase that was then followed by 'a diminution in anxiety and activity as the child sinks into a mute, manneristic and unoccupied state'. If the condition arose at this age, it was often mistaken for an organic dementia. Finally, psychosis could onset in the middle or late years of childhood, in which case the regression was minimal but 'the behaviour is compulsive and "odd" and there is a preoccupation with natural phenomena'. This condition could be mistaken for 'severe obsessional states', but Anthony regarded it as most definitely a manifestation of psychosis. When describing these different phases, it is clear that Anthony's understanding of autism drew directly from Bleuler and Piaget and not from Kanner. ${ }^{123}$

Anthony argued that the age at which a child developed autism or psychosis affected the particular form that the disorder took. His distinction between different ages of onset was framed by the conviction that 'every infant begins its psychological life in an autistic state.' Using a concept borrowed from Freud's Beyond the Pleasure Principle, Anthony employed a 'barrier hypothesis' to explain the development of different types of autism in children. The concept of an 'autistic barrier' had 
entered literature on adult schizophrenia and it was thought that psychotherapy could 'break through' that barrier. ${ }^{124}$ As Anthony described it, during normal development, the constitutional barrier that protects the infant is supplemented by a maternal barrier, which eventually gives way to an 'autonomous ego barrier'. This barrier enables the child to focus and not to be distracted by every passing stimulus. In the case of primary autism in the 'first age' group, the infant's constitutional barrier is 'abnormally thick' and the infant then goes on to develop 'an unselective psychotic barrier with the result that he fails to emerge from his primary autism'. In cases of secondary autism, or the second and third age group, the constitutional barrier is 'abnormally thin', allowing an excessive amount of stimulation to affect the psychotic child's ego. In this situation, he 'withdraws behind a thick, unselective psychotic barrier which blankets the stimulation' (Figure 2). ${ }^{125}$

Anthony maintained that the causes of childhood psychosis were numerous and often took place simultaneously. He therefore postulated an amalgam of forces that include 'constitutional, organic, genetic and psychogenic determinants and possibly some still unknown factor. ${ }^{126}$ Anthony strongly urged against any 'monocausal' view of the condition, especially that which placed excessive emphasis on 'schizophregenic' or 'psychotogenic' parents. The role of disturbed parents in the aetiology of the condition had been raised by Kanner as well as several other American doctors, such as William Goldfarb from the Henry Ittleson Center, whose evidence Bowlby had relied upon heavily in his WHO report. ${ }^{127}$ Goldfarb had described the mothers of autistic children as 'wooden', and argued that these mothers added to the confusion of their children by lacking any form of direction. ${ }^{128}$ Anthony took issue with both of these accounts as they seemed to suggest that bad parenting could be the sole cause of childhood psychosis. As he put it, in an attempt at clarification: "Not all "psychotogenic" mothers produce psychotic children; nor are all the children of "psychotogenic" mothers psychotic or the mothers of psychotic children "psychotogenic." ${ }^{129}$ On the other hand, he also criticised doctors and researchers who placed too much emphasis on 'organic' or 'constitutional' factors in causation. He admitted that there were always cases in which organic factors may have played a part. For example, Bender had identified neurological damage and evidence of encephalitis and encephalopathy in some of her cases of childhood schizophrenia. However, Anthony warned 


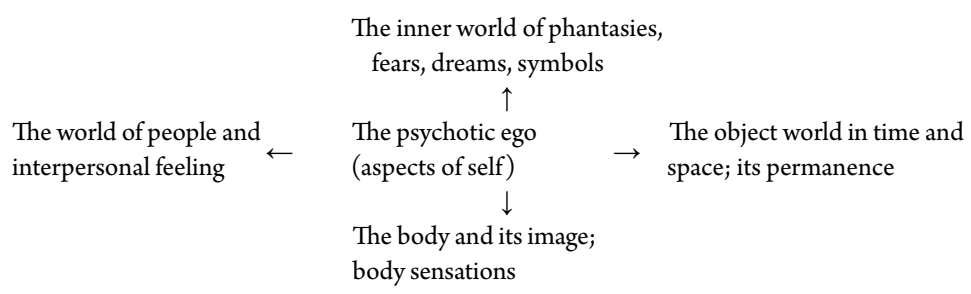

The failure to relate:

The defects

1. The ego to the inner self (asymbolia, absence of dreams, confusion of inner phantasy with outer reality).

2. The ego to itself (lack of self-recognition, self-consciousness, ego boundaries, selfidentity; dysidentity)

3. The ego to objects (no object concept, impermanence of objects, no conservation or constancy; $a$-dualism).

4. The ego to people (constriction and diminution of feeling, inability to give or reciprocate; $a$-cathexis).
5. The ego to its body (inadequate body image, poor localization of sensation and pain, poor co-ordination; poor representation).

\section{The defences}

1. Perseveration, rigidity' just-so' behaviour, stereotypy, repetition, circular behaviour, replacement activity.

2. Withdrawal, pseudo-deafness, visual evasion, raised sensory thresholds, going under cover.

3. Transitional relationships to inanimate objects.

4. Projection, introjection, denial.

Figure 2 Chart, 'The psychotic ego with its defects and defences', from Elwyn James Anthony, 'Group therapeutic techniques for residential units', Case Conference 4, no. 6 (1957)

against making direct correlations between cause and effect in childhood psychosis. Taking the 'multicausal' view, he drew up a 'diagnostic schema' listing five different continua on which all cases of childhood psychosis could be placed. They could be placed on either a 'normal', 'deficiency', 'organic', 'neurotic' or 'psychopathic' continuum. Once identified on one of these continua, the severity of the child's disturbance could also be measured 'in terms of withdrawal, regression, rigidity, [and] the presence or absence of organic involvement. ${ }^{130}$

Anthony's aim was to (re)integrate psychoanalytic theory into the Piagetian scheme of subjective development to enable the detailed description of both normal and abnormal infantile thought. ${ }^{131}$ In the developmental model that he put forward, the initial stages of a child's life were said to be characterised by primary narcissism or egocentrism in which 'the self and the environment are one and there are no permanent 
external objects. ${ }^{\prime 132}$ The emergence of self-awareness occurred after the child, as organism, ceased to function through pure reflex action and came to use 'inventive action' to grasp and direct objects in space. This emergent intellectual ability was paralleled with a new emotional ability to relate to objects. As Anthony described it, 'the child was only able to proceed to a full emotional relationship with objects after he had rendered them permanent and substantial. ${ }^{133}$ After the child recognised the existence of other objects in the world, he began to adapt to his environment through the psychological processes of 'assimilation' and 'accommodation'. Assimilation consisted of the mental incorporation of objects in the environment that fulfilled the organism's, or the child's, individual needs. Accumulated incorporated objects in the mind formed elementary structures called schemata. Accommodation was the process whereby the child adapted these internal schemata to fit with the external environment and then directed his interactions with real external objects. Anthony considered Piaget's assimilation-accommodation mechanisms to be largely analogous to the projection-introjection mechanisms of psychoanalytic theory. In the assimilation-accommodation mechanism, however, there was a feedback system that created the 'logical machine' of the child's mind. By contrast, the projection-introjection processes led to the formation of the child's sense of self. Anthony speculated that perhaps, if one considered the result of these processes together, 'the logical machine might almost be described as the ego-ideal of the Piagetian intellectual system.' ${ }^{134}$

'Psychotic' children were children in whom normal identification processes had failed. Anthony claimed that the 'psychotic ego' failed to draw a distinction between inner phantasy and outer reality, resulting in an 'asymbolic' state of mind. The 'psychotic ego' was also unable to establish a relation to external objects, leaving it without a sense of object permanence and constancy. In addition, it could not relate to people and neither could it relate to its body or its self. This inability to relate to definable objects and identities left it in a state of defence that resulted in stereotyped behaviour and a withdrawal from sensory experiences. The psychotic child then formed 'transitional relationships to inanimate objects' and engaged in 'projection, introjection' and 'denial.' ${ }^{135}$

Anthony argued that psychotic children exhibited 'curious disturbances of object and space-time development' that could shed light on normal perceptual development in infants and children. His eventual 
aim was to use observations from the psychotic clinic in order to develop new theories of psychological development in children. His 'style of reasoning' about childhood psychosis was an individualistic, case-based style of thinking that drew from wider scientific theories on children's 'normal' psychological development and the 'organic' factors that could affect it.

Nevertheless, the work that Anthony was able to conduct at the Maudsley was limited by the Mental Deficiency Act 1913 and the Education Act 1944. Because these Acts enforced statutory care for children who were considered to be 'ineducable', children who supposedly had the most active phantasy lives, whose cases were regarded as exemplars of the autistic mind, were in practice those children most likely to be sent to defective institutions and thus taken furthest away from the Maudsley psychological and observational gaze. This was clearly not the wish of doctors such as Anthony and Cameron, who wanted to build conceptual frameworks for psychology around such cases. It was not until these Acts were overturned that new psychological theories could be constructed around the autistic mind. However, by this time, other political and legal changes meant that the study of 'psychosis' and 'autism' within a wider theory of individual child development was no longer viable. Anthony moved to the USA to become Ittleson Chair of Child Psychiatry at Washington University Medical School, St Louis. His ideas about autism would be fundamentally reshaped by later Maudsley researchers interested in childhood psychosis who came to focus on the importance of statistical reasoning in framing the concept.

Although psychological models were built around them, the children who attended the first psychotic clinic in Britain would actually grow in significance post-1959. This is because it was from this clinic that the first cases of 'autism' were selected for statistical studies that would sow the seeds for autism spectrum-making within child psychology.

\section{Statistics, schizophrenia and the growing significance of the Institute of Psychiatry}

Statistical approaches to the measurement of unconscious instinctive drives in children, such as those sought to be developed by Burt, hit a brick wall in the 1950s due to the major controversies concerning the 
description of infantile thought. In 1950, Glover founded the British Journal of Delinquency and it was primarily via this outlet, as well as the ISTD, that medically trained child psychiatrists employed statistical research on the criminal tendencies of children. Several Maudsley doctors, such as T. C. N. Gibbens and Wilfred Warren, published in the journal in the 1950s. This work used statistical methodologies in innovative ways, fusing psychoanalytic and case-based 'styles of reasoning' with statistical analyses. Although some people, such as Glover, continued to think about the role of instincts in the development of delinquency and criminality, on the model of child guidance, their statistical studies of atypical development were based on simple outcome measures of criminal behaviour. ${ }^{136}$ The possibility of integrating atypical versions of child development into a comprehensive theory of psychological development, objectively measured, was only possible if psychologists were able to measure, using psychological tools, the emergence of selfidentity in infants and children. Until that was possible, there could be no proof for theories in developmental psychology regarding the role of instinctive drives in structuring the personality.

Aubrey Lewis had supported research into mental deficiency at the Unit for Research in Occupational Adaptation not only because it could lead to better training and productive potential, but also because defectives provided 'a rewarding field for systematic enquiry' since their problems were 'less diverse and elusive, and lend themselves rather more readily to measurement, than those of most other branches of psychiatry.137 However, actual research into mental deficiency proved the fallacy of such ideas. In 1956, Jack Tizard and Neil O'Connor claimed that the categories of mental disorder and mental deficiency are frequently confused and probably interrelated.' ${ }^{138}$ This similarity had been adduced through the study of defectives' behaviour. As O'Connor and Tizard put it, 'In the general behaviour of defectives, psychiatrists have frequently detected features similar to those seen in psychosis. "Psychotic" cases are to be found among imbeciles, and patients may, because of psychosis, score on some tests at the performance level of imbeciles. ${ }^{139}$ Because Maudsley researchers were using objective measures for personality, they could not see the theoretical distinctions that had previously been drawn between defective and schizophrenic populations. Their amalgamation of the defective and schizophrenic categories was an artefact of their testing methods. ${ }^{140}$ 
Similarities between the two categories were also made in the USA during the 1950s, where comparable changes in the organisation of welfare provision had brought defective populations to the attention of sociologists and psychologists. ${ }^{141}$ By the late 1950s, Clemens E. Benda, who had assisted Binswanger at the Bellevue Hospital in Switzerland in the early 1920s and was then working as medical director of the Walter Fernald School for 'mentally retarded' children in Massachusetts, ${ }^{142}$ argued that when 'applying psychiatric standards to behavioural patterns, the idiot is almost, by definition, an "autistic" child.. ${ }^{143}$ By the end of the decade, mentally defective populations had been drawn into the general study of psychiatry. When applying statistical methodologies, the behaviour and performance problems of 'defectives' were directly analogous to those observed in 'schizophrenics'.

The application of simplified tests of personality thus blurred the boundaries of mental defect and schizophrenia, to such an extent that this began to further challenge the divisions inherent in psychological theory and again to highlight the fallacy of 'mental defect' as a concept. The challenge to this concept came in the form of not only schizophrenia research but also further analysis into the validity of the claim that 'mental defect' was a clearly definable and heritable condition. In conjunction with Anthony and Cameron's work, researchers at the MRC Unit challenged the laws that were preventing 'psychotic' children from developing to their full potential. By maintaining contact with Steiner schools and others, they began to argue that with the correct education and treatment, 'psychotic' children could develop beyond their psychotic state. They called for more research to enable a greater understanding of the psychological development of children found to perform badly in standard intelligence tests.

In 1957, Brian Kirman and L. T. Hilliard from the Fountain Hospital drew attention to the fact that the psychological term 'mental deficiency' encompassed a number of different psychological and physical states. In their attempts to integrate this category into general psychology, Kirman and Hilliard were interested in genetic transmission and deficiencies or aberrations during gestation that affected the development of the brain. In 1938, Lionel Penrose, a medical doctor based at the Royal Eastern Counties Institution in Colchester, had conducted a Clinical and Genetic Study of 1280 Cases of Mental Defect in which he had argued that 'mental deficiency' was hereditary. ${ }^{144}$ Penrose had drawn 
distinctions between different forms of mental deficiency, arguing that phenylketonuria, amaurotic idiocy, microencephaly and some types of cretinism, deaf mutism and congenital diplegia were transmitted genetically in a recessive manner. However, Kirman criticised Penrose's distinctions, arguing that some of these conditions, microencephaly for example, were not disease entities and thus atypical forms of the condition could be generated by other factors, such as deficiencies or aberrations during gestation. Of these, viral infections, bacterial and protozoal infections, irradiation, chemical imbalances and hormonal imbalances could all contribute to the production of birth deformities. ${ }^{145}$ In making these claims, Kirman drew evidence from a growing number of animal studies conducted during the 1950s into congenital malformation, such as Eayrs' study of thyroid function in gestating rats and Hicks' work on the irradiation of pregnant animals by X-ray. ${ }^{146}$ Kirman pointed out that the exact cause of mental deficiency was still only ascertained in very few cases, despite the growing research into the topic. In a study conducted at the Fountain Hospital in 1955, the pathological cause of defect was confirmed in only 17 out of 154 cases, despite the fact that countless tests had been conducted at leading London hospitals. ${ }^{147}$ However, Kirman and Hilliard highlighted that it was important to bring knowledge of these conditions into the wider domain of general psychology, however unusual they may be. They described cases of microcephaly, hydrocephalus and acrophalosyndactyly, a disorder in which the limb buds do not develop properly and the head grows disproportionately in height. ${ }^{148}$ All of these conditions were associated with the psychological state 'mental deficiency', but they were all unique conditions and this problematised the use of the general concept in psychological theory.

In the case of less obvious abnormalities, Kirman and Hilliard collected information from patients at the Fountain concerning their general medical and social history. The purpose of this was to identify both the social factors that may cause mental deficiency as well as the social problems that may result from it. Kirman argued that these two groups of problems were 'difficult to disentangle' and that they clearly 'interact with each other'. He overtly criticised the previous standard textbook on Mental Deficiency by Alfred Frank Tredgold from University College Hospital. Tredgold had maintained that defectives were produced in families in which there was a large amount of 'mental abnormality' forming what he called a 'psychopathic diathesis'. 
Kirman countered that 'It is possible on such a hypothesis to list all forms of deviation from an approved mean of social behaviour in the family of a mental defective as evidence of a "psychopathic diathesis." 'Kirman and Hilliard instead sought to offer a new model of mental deficiency in which either the physical abnormalities of the body and brain were clearly identified, or the causes were opened out into the realm of more sophisticated sociological research. ${ }^{149}$

In 1955, Beate Hermelin and A. D. B. Clarke published an article on the 'abilities and trainability' of 'adult imbeciles'. They argued that the problem of training imbeciles was becoming increasingly important because the post-war decline in infant mortality and the advent of new drugs had 'prolonged their life-span and hence [increased] their numbers. ${ }^{150}$ Up until the 1950s, British writers on mental deficiency had always regarded the problem as a failure of normal development, hence the epithet 'deficiency'. Hillard and Kirman considered that their problems may be the result of physical 'disorders of gestation' causing 'somatic as well as neural' abnormalities. They also considered the importance of birth injury and post-natal infections or 'chemical, nutritional and endocrine causes' that affected the development of the brain and body. This brought a new dimension to the approaches that could be taken to 'mental deficiency' as a psychological problem. ${ }^{151}$

Because neither intelligence measures nor behaviourist observations could be used to track all psychological development in children, the detailed observation and study of 'mental defectives' and 'childhood schizophrenics' promised to bring a new dimension to the understanding of the way that biological abnormalities and instinctive drives impacted upon the development of self-identity and enabled socialisation in children.

Nevertheless, it was Bowlby and Winnicott's work on child psychology that was widely known in the public domain, not the Maudsley work. This skewed public understanding of autism and stoked further controversy. It is notable that even Kanner argued that the description of autism was being overused in the 1950s and that the USA 'seemed to be populated by a multitude of autistic children' whose condition appeared to be caused by faulty 'maternal emotional determinants. ${ }^{152}$ Although it was clearly a problem that parents were being unduly criticised, the more general engagement with parents occurring in this period, in which families were brought into a wider nexus of educational and psychological 
services to support child development, was a positive move. Childhood schizophrenia and autism became caught up in a wider trend for governmental agencies to observe and adapt parental behaviour. The 1950s were a problematic decade for child psychologists and for children who were observed under this rubric. Whereas, on the one hand, child psychologists such as Bowlby fought for their descriptions of instinctive drives and attachments in children to be taken seriously and to frame new political approaches to social interaction, on the other hand social reformers and psychologists like Jack Tizard sought to improve the integration of 'mentally defective' and 'mentally ill' children and adults, failing to appreciate the radical challenge that this would pose to theories of normal psychological development. Bowlby's argument that 'maternal deprivation' was just like nutritional deprivation in the marked effects that it had on an infant's brain development and precious psychological structures rang loud. Nevertheless, whilst this was represented as laudable advocacy of an infant's right to care in some cases, it did not make sense to extend the theory to all children with 'mental deficiency' or sensory defects of sight or hearing. It was not just psychiatrists and mental deficiency specialists who criticised the logic of mother blaming. For example, by the mid-1950s, Anna Freud had begun to take issue with Bowlby's interpretation of her observational evidence from the Hampstead nurseries. She claimed that he was paying too much attention to external circumstances, the actual mother-child relationship, whereas the aim of psychoanalysis was always to look at mental representations of instinctive drives and external relationships, not to look at the relationships themselves. ${ }^{153}$ However, because of the social and cultural capital of Bowlby's theories, it would only be after 'mental defectives' were fully integrated into models of society that they could be fully integrated into models of psychology.

\section{The problem with the 1950s}

Although Anthony was beginning to rethink the relationship between mental defect and mental illness, he was still drawing from psychological and psychoanalytic models of social development and the formation of relationships that were based only on homogenised population groups. Because psychological theories of child development and relationship 
formation discounted the most interesting and significant section of the population when it came to child development, it was unusual that psychiatrists describing very atypical children would employ them. And yet, there was really nothing else for them to draw upon without causing a crisis of confidence not only in psychological theory, but also in the institutions that were based upon it, in particular institutions for 'mental defectives', as well as in the structure of the school system. Concepts of intelligence and instinct theory had become ingrained in English and North American culture by the mid-1950s and it was virtually impossible to challenge them. Theories of relationship formation, even those as radical as those put forward by Melanie Klein, were all basically formed around that model and it was impossible to think about child development without thinking about instinctive drives towards relations and social interactions, and measurements of intelligence.

Instead of challenging the monoliths of instinct theory and the theory of intelligence, some researchers tried to surreptitiously integrate very atypical children into models of normal psychology. In Britain, most clinicians were not particularly concerned with Kanner's work in the 1940s and early 1950s but were instead desperate to present wholesale theories of social development. They regarded psychosis, schizophrenia and autism as handy concepts to throw into this description. The significant legal changes witnessed at the end of the 1940s in Britain ensured that children diagnosed with schizophrenia or psychotic disorders became increasingly important subjects for psychological investigation. Children diagnosed with these disorders promised to answer the pressing conceptual issues in psychology, psychoanalysis and psychiatry and a flurry of research built up around them. In Britain, Maudsley doctors Elwyn James Anthony and Kenneth Cameron experimented with physical and behavioural methods to alter the development of schizophrenic psychopathology and attempted to place schizophrenic children on a spectrum with other psychological states. Melanie Klein, Susan Isaacs and Anna Freud continued to research the significance of primary narcissism to understanding both normal and pathological development.

In general, there was a disciplinary and institutional gap between those working on general child development and socialisation, such as Isaacs and Lowenfeld, and those working on severe psychopathology such as Creak and Anthony, the latter based in hospitals whilst the 
former worked in nurseries, child guidance clinics and university psychology departments. When their theories collided, they did so in a way that was slightly haphazard. Although psychiatrists such as Anthony and Cameron were treating children with very severe psychopathology, they were importing their models of normal or general psychological and social development from researchers such as Isaacs and Piaget, who had quite different objectives in their descriptions of 'autism'. The result was a fusion of models drawn from the observation of severe psychopathology in adults with those drawn from the observation and study of typical behaviour and development in infants and children.

Whereas North American writers tended to turn to Gesell for a description of normal development, Anthony turned to Piaget. This was significant because Piaget was obviously more interested in the development of children's thought as a system of advancing logic, and interpreted this from a philosophical standpoint. In Britain, it was unlikely that Anthony would have followed any other direction given the significance of Isaacs' theories and her reliance on Piaget. What this meant in practice was that British descriptions of childhood schizophrenia, psychosis and autism were framed within a very particular theory of social development, conceptual awareness and the construction of logic in a child's mind. Furthermore, Gesell was more interested in describing typical developmental behaviours forming from the foetal infant onwards, whereas Piaget was not interested in behaviour per se, but was focused on the description of children's logical thinking. To put it another way, an infant who learned about the social world through his bodily behaviour, and one who learned about it through his ability to think logically, constituted very different beings. These differences would become more marked with the creation of the psychology of autism spectrum-making in the 1960s. In the 1950s, there were still too many obstacles to research in atypical child development and it would take a revolution before this problem would be overcome.

\section{Notes}

1 In Scotland, the 1945 Education (Scotland) Act initiated this process.

2 Savage, Identities and Social Change in Britain since 1940.

3 Healy, The Anti-Depressant Era.

4 K. Jones, A History of the Mental Health Services, p. 293. 
5 Shorter, A History of Psychiatry; Grob, From Asylum to Community; Healy, The Creation of Psychopharmacology.

6 Showalter, The Female Malady.

7 Riley, War in the Nursery.

8 Dicks, 50 Years of the Tavistock Clinic, p. 207.

9 Miller and Rose, 'The Tavistock Programme'.

10 Institute of Psychiatry Archives, Annual Report, 1950-1951, p. 3.

11 O'Connor, 'The origins of the Medical Research Council Social Psychiatry Unit'.

12 Derksen, 'Science in the clinic', pp. 271-274.

13 Derksen, 'Science in the clinic'.

14 Meaning psychoanalytic psychotherapy. Eysenck, Rebel with a Cause, pp. 127-129.

15 Eysenck, Dimensions of Personality.

16 Eysenck, Rebel with a Cause, pp. 96-97; Jung, Psychological Types, p. 413.

17 Report of the Care of Children Committee, Cmd. 6922 (London, 1946).

18 Handicapped Pupils and School Health Regulations, 1945, quoted in Phtiaka, Special Kids for Special Treatment?, p. 9.

19 Kahn, 'The local authority child guidance clinic'; Warren, 'You can never plan the future by the past', 244-245; Wardle, 'Twentieth-century influences', 58; Kier, 'A history of child guidance', 5-6.

20 Hersov, 'Child psychiatry in Britain', 784.

21 Institute of Psychiatry, Annual Report, 1950-1951, pp. 1-3.

22 Henderson and Gillespie, A Text-book of Psychiatry for Students and Practitioners.

23 Maudsley Hospital Childhood Psychosis/Autism Archive (all case numbers have been anonymised) MHCP/A: 448773: Letter - Cameron to Frederic De Havas, Salmon's Cross School, 21/7/54; MHCP/ A: 979317: Letter from L. Wilson (Maudsley Registrar), 20/6/55.

$24 \mathrm{MHCP} / \mathrm{A}: 573500$ : Letter - Cameron to Cashmore, 28/10/58.

25 MHCP/A: 926185: Letter - Creak to Dr Elliot, County Medical Officer, County Hall, Maidstone, 24/6/55.

26 MHCP/A: 573500: Letter - Cashmore to Anthony, 30/10/57.

27 American Psychiatric Association [APA], Diagnostic and Statistical Manual (First edition, 1952), p. 12.

28 APA, Diagnostic and Statistical Manual, p. 28.

29 Rose, Governing the Soul, pp. 176-177. 
30 Hersov, 'Child psychiatry in Britain', 785.

31 Cameron, 'Diagnostic categories in child psychiatry', 67.

32 O'Gorman et al., 'Psychoses in childhood', 603.

33 O'Gorman et al., 'Psychoses in childhood', 603.

34 E.g. O'Connor, 'Neuroticism and emotional instability'; O'Connor and Tizard, The Social Problem of Mental Deficiency.

35 Venables, 'Experimental psychological studies of chronic schizophrenia', p. 83.

36 Venables, 'Factors in the motor behaviour of functional psychotics'; Venables, 'Experimental psychological studies of chronic schizophrenia'.

37 O'Gorman, 'Psychoses in childhood', 602.

38 Creak, 'Psychoses in childhood' (1951).

39 B. W. Richards, 'Childhood schizophrenia and mental deficiency', 303.

40 Benda et al., 'The inadequacy of present-day concepts in mental deficiency'.

41 Bergman et al., 'Schizophrenic reactions during childhood in mental defectives'.

42 Kanner, 'Emotional interference with intellectual functioning'; Kanner, 'The conception of wholes and parts in early infantile autism'.

43 E.g. Le Vann, 'A concept of schizophrenia in the lower grade mental defective'; Kugelmass, Management of Mental Deficiency in Children.

44 Harms, 'Essential problems regarding our present knowledge'; Bakwin, 'Etiology of behavior disorders'; Bakwin, 'Early infantile autism'; Ackerman, 'Psychiatric disorders in children'; Kestenberg, 'The history of an autistic child'; Kestenberg, 'Pseudo-schizophrenia in childhood and adolescence'; Clardy, 'A study of the development and course of schizophrenia in children'.

45 Eickhoff, 'The aetiology of schizophrenia in childhood', 230.

46 Gardner, 'Childhood schizophrenia', 520-521.

47 Freedman, 'Childhood schizophrenia', 487-488.

48 Anthony, 'An experimental approach: Autism', 211-212.

49 Flapan, 'The ongoing journey of an extraordinary man'.

50 Institute of Psychiatry, Annual Report, 1950-1951, p. 13; Shepherd, Conceptual Issues in Psychological Medicine, p. 134.

51 Institute of Psychiatry, Annual Report, 1951-1952, p. 15.

52 Hersov, 'Child psychiatry in Britain', 793.

53 Anthony, 'An experimental approach: Encopresis', 146; Anthony, 'Group therapeutic techniques for residential units'; Anthony, 'Other people's 
children'; Anthony, 'The system makers'; Anthony, 'The significance of Jean Piaget for child psychiatry'.

54 American Psychoanalytic Association, 'Annual meetings of the APA 1960', pp. 724-741.

55 Anthony, 'The system makers', 255-269.

56 Anon., 'Kenneth Cameron: Obituary'; Cameron, 'A psychiatric inpatient department for children'; Cameron, 'Symptom classification in child psychiatry'; Cameron, 'Diagnostic categories in child psychiatry'.

57 Nolan, A History of Mental Health Nursing.

$58 \mathrm{MHCP} / \mathrm{A}$ : 874753: 'Record for nursing staff: Instructions from doctor', $26 / 10 / 1954$.

59 MHCP/A: 874753: Nurses' notes, 19/10/54-26/10/54.

$60 \mathrm{MHCP} / \mathrm{A}:$ 874753: Nurses' notes, 30/10/54.

$61 \mathrm{MHCP} / \mathrm{A}: 338427$ : Nurses' notes, 20/3/55.

$62 \mathrm{MHCP} / \mathrm{A}: 573500:$ Nurses' notes, 9/10/58.

63 MHCP/A: 772931: Nurses' notes, 27/2/58.

$64 \mathrm{MHCP} / \mathrm{A}: 636380$ : Inpatient summary, 1958.

65 MHCP/A: 874753: Case summary, c. 1954.

66 MHCP/A: 386165: Nurses' notes, 23/10/55.

$67 \mathrm{MHCP} / \mathrm{A}: 207036:$ Nurses' notes, 15/5/57.

$68 \mathrm{MHCP} / \mathrm{A}: 338427$ : Nurses' notes, 26/3/55.

69 MHCP/A: 436751: Nurses' notes, 18/11/53.

70 MHCP/A: 893951: Nurses' notes, 29/10/53.

71 Anthony, 'An experimental approach: Autism', 212.

72 Rutter, 'Behavioural and cognitive characteristics', pp. 53-55.

73 WHO, Proceedings of the First Meeting.

74 Anthony, Clinical Aspects of Childhood Psychosis [film].

75 Tulsky et al., 'Historical overview of intelligence and memory', pp. 23-28.

76 Lickorish, 'Psychological tests in child psychiatry'; Weschler, Weschler Intelligence Test for Children.

77 Gould, The Mismeasure of Man, pp. 188-189; Sutherland and Sharp, Ability, Merit and Measurement, pp. 126-127; Richards, Putting Psychology in Its Place, pp. 253, 285.

78 Galison, 'Image of self'.

79 Galison, 'Image of self', p. 267.

80 Richards, Putting Psychology in Its Place, p. 146.

81 Kramer et al., 'Whirling as a clinical test in childhood schizophrenia'. 
82 Helen Mehr, 'The application of psychological tests and methods', 90; Anderson and Zahm, 'Obituary: Helen Margulies Mehr (1916-1992)'; Mosse, 'The Duess test', 230-236.

83 Montague, 'Spontaneous drawings of the human form in childhood schizophrenia'.

84 WTA: PP/LOW/C/19. Lowenfeld, 'A combined approach to the study and treatment of disturbed children'

85 Montague, 'Spontaneous drawings of the human form in childhood schizophrenia'.

$86 \mathrm{MHCP} / \mathrm{A}:$ 'Draw a man' pictures, 1950s.

$87 \mathrm{MHCP} / \mathrm{A}:$ 436751: Report by Pines, 9/9/52.

$88 \mathrm{MHCP} / \mathrm{A}$ : 436751: Reports by Margaret Newell, Staff Psychologist, November 1955.

$89 \mathrm{MHCP} / \mathrm{A}:$ 436751: Letter from Anthony, 7/5/56.

$90 \mathrm{MHCP} / \mathrm{A}$ : 636380: Formulation and inpatient summary by Cameron and Kreitman.

$91 \mathrm{MHCP} / \mathrm{A}:$ 636380: Letter - Kreitman to Hulbert, 14/7/58.

$92 \mathrm{MHCP} / \mathrm{A}:$ 636380: Letter - Hulbert to Kreitman, 14/7/58.

$93 \mathrm{MHCP} / \mathrm{A}:$ 636380: Letter - Kreitman to Hulbert, 14/7/58.

94 MHCP/A: 636380: Psychological tests, 'Analysis of speech', 20/8/58.

95 E.g. MHCP/A: 772931: Letter from Cameron, 7/11/58.

96 Anthony, 'An experimental approach: Autism', 223-224.

97 Cameron, 'Psychoses in infancy and early childhood', 280.

$98 \mathrm{MHCP} / \mathrm{A}:$ 887704: Insulin treatment chart, 3/8/1950-11/01/1951.

$99 \mathrm{MHCP} / \mathrm{A}:$ 887704: Inpatient medical notes, 14/11/50.

100 Cameron, 'Psychoses in infancy and early childhood', 283.

101 E.g. MHCP/A: 563119: BMMA Case Summaries 1948/S BMF/5 (Author's code: 869086 ).

102 Scott and Clifford, 'Psycho-analytic concept of depression', p. 540.

103 MHCP/A: 470968: Oftedal's notes, 1952-1953.

104 E.g. $\mathrm{MHCP} / \mathrm{A}: 338427$ : OT report, 20/12/54.

$105 \mathrm{MHCP} / \mathrm{A}: 681884$ : OT report, 12/12/53.

$106 \mathrm{MHCP} / \mathrm{A}:$ 573500: Letter, 29/10/58.

$107 \mathrm{MHCP} / \mathrm{A}:$ 948758: Letter - König to Cameron, 19/6/52.

$108 \mathrm{MHCP} / \mathrm{A}$ : 532153: Letter - De Havas to Cameron, 12/12/55.

$109 \mathrm{MHCP} / \mathrm{A}:$ 948758: Letter - König to Cameron, 19/6/52.

$110 \mathrm{MHCP} / \mathrm{A}$ : 772931: Letter - De Havas to Cameron, 22/10/57.

$111 \mathrm{MHCP} / \mathrm{A}:$ 563119: Report of case, 15/10/52. 
$112 \mathrm{MHCP} / \mathrm{A}:$ 874753: Letter - Anthony to Bradshaw, 22/9/54.

113 MHCP/A: 772931: Prospectus - St Agnes' School, 1958.

114 E.g. Shorter, A History of Psychiatry.

115 Hilliard, '(b) Mental deficiency aspects'.

116 Spencer, 'The revision of the Mental Health Act, 1959'.

117 Spencer, 'The revision of the Mental Health Act, 1959', 84.

118 J. K. Wing, 'Diagnosis, epidemiology, aetiology'; Rutter, 'Behavioural and cognitive characteristics', pp. 16, 55.

119 Anthony, 'An aetiological approach to the diagnosis of psychosis in childhood', 94.

120 Anthony, 'An aetiological approach to the diagnosis of psychosis in childhood', 91.

121 Anthony, 'An experimental approach: Autism', 216.

122 Bender, 'Clinical study of one hundred schizophrenic children', 53.

123 Anthony, 'An aetiological approach to the diagnosis of psychosis in childhood'; 91-92.

124 Betz, 'A study of tactics for resolving the autistic barrier'.

125 Anthony, 'An experimental approach: Autism', 218.

126 Anthony, 'An aetiological approach to the diagnosis of psychosis in childhood', 93.

127 Meyers, 'Obituary: William Goldfarb', 391-392.

128 Goldfarb, quoted in Anthony, 'An aetiological approach to the diagnosis of psychosis in childhood', 92.

129 Anthony, 'An aetiological approach to the diagnosis of psychosis in childhood', 92.

130 Anthony, 'An aetiological approach to the diagnosis of psychosis in childhood', 95.

131 Anthony, 'The system makers'.

132 Anthony, 'The system makers', 262.

133 Anthony, 'The system makers', 258.

134 Anthony, 'The significance of Jean Piaget for child psychiatry', 22.

135 Anthony, 'An experimental approach: Autism', 212.

136 Shaw, 'ISTD Summer School, 1950', 150-151; Glover, The Diagnosis and Treatment of Delinquency, p. 15; Warren, 'Conduct disorders in children aged five to fifteen years', pp. 164-186.

137 Lewis in O'Connor and Tizard, The Social Problem of Mental Deficiency, p. vi.

138 O'Connor and Tizard, The Social Problem of Mental Deficiency, p. 60. 
139 O'Connor and Tizard, The Social Problem of Mental Deficiency, p. 52.

140 Tizard and Venables, 'Reaction time responses by schizophrenics, mental defectives and normal adults'.

141 E.g., Franz Kallmann et al., 'The role of mental deficiency in the incidence of schizophrenia'; Sarason, Psychological Problems in Mental Deficiency.

142 Freud et al., The Sigmund Freud-Ludwig Binswanger Correspondence, 1908-1938, p. 172. Benda's name has more recently been associated with radiation experiments conducted on children at the Walter Fernald School; Moreno, Undue Risk.

143 Benda, Developmental Disorders of Mentation and Cerebral Palsies, quoted in Bender, 'Autism in children with mental deficiency'.

144 Penrose, A Clinical and Genetic Study of 1280 Cases of Mental Defect.

145 Penrose quoted in Hilliard and Kirman, Mental Deficiency, pp. 53-56.

146 Hilliard and Kirman, Mental Deficiency, pp. 61-62.

147 Hilliard and Kirman, Mental Deficiency, p. 53.

148 Hilliard and Kirman, Mental Deficiency, pp. 355-367.

149 Hilliard and Kirman, Mental Deficiency, p. 33.

150 Clarke and Hermelin, 'Adult imbeciles', 337.

151 Hilliard and Kirman, Mental Deficiency, pp. 61, 66, 68.

152 Kanner, 'Infantile autism and the schizophrenias', 413.

153 Vicedo, The Nature and Nurture of Love, pp. 132-137. 